\title{
Mortalidade por causas externas no estado do Rio de Janeiro no período de 1976 a 1980
}

\author{
Célia Landmann Szwarcwald* \\ Euclides Ayres de Castilho*
}

O presente trabalho teve por objetivo o de determinar as tendências da mortalidade por causas externas no periodo de 1976 a 1980, no Estado do Rio de Janeiro. Foram estudadas as principais causas externas de óbito e sua distribuição temporal e espacial. Os acidentes de trânsito de veiculo a motor se revelaram como a principal causa externa de morte e, entre eles, os atropelamentos mostraram-se de real gravidade, sobretudo entre as crianças em idade escolar (5 a 14 anos). O estudo revelou um aumento de $70 \%$ na taxa de homicidios nos 5 anos pesquisados, e estes já se constituem no principal fator de mortalidade entre os adultos jovens de 20 a 29 anos. Evidenciou-se, também, grande número de óbitos classificados como "lesões ignoradas se acidental ou intencionalmente infligidas", apontando para falhas no sistema de classificação dos óbitos por causas externas no Estado do Rio de Janeiro.

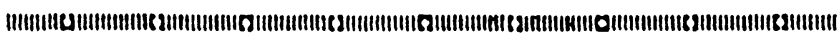

O Rio de Janeiro apresenta uma das maiores taxas de mortalidade por causas externas, quando comparado aos outros estados do Brasil ${ }^{2} 4$ de 1970 a 1980 esta taxa cresceu de $35 \%$, passando de 73 para 99 por 100.000 habitantes $^{5}, 9$. Contribuiu para este aumento o grande número de homicídios que vem se elevando a cada ano.

Apesar da violência ser um grave problema do Rio de Janeiro, análises da mortalidade por causas externas não são disponíveis para este estado. Entre os estudos realizados recentemente no País sobre este tema, destacamos a pesquisa de Mello Jorge, M.H.P. ${ }^{19,20,21,22}$ com estudo detalhado das mortes acidentais e violentas desde 1950 até a época atual, no Município de São Paulo. Barros. M. B. de A. ${ }^{1}$, em trabalho apresentado no III Seminário Latino-Americano de Medicina Social, desenvolveu um estudo descritivo em trabalho apresentado no III Seminário Latino-Americano de Medicina Social, desenvolveu um estudo descritivo da mortalidade por lesões e envenenamentos no Brasil, em 1980 , utilizando as estatísticas publicadas pela Secretaria Cadernos de Saúde Pública, R.J., 2 (1):19-41, jan/fev, 1986.
${ }^{*}$ Depto. de Epidemiologia e Métodos Quantitativos em Saúde ENSP - FIOCRUZ
Rece bido para public ação em $30 / 04 / 85$ 
Nacional de Ações Básicas do Ministério da Saúde ${ }^{5}$. No mesmo Seminário, Nunes, E.D. ${ }^{25}$ apresentou uma revisão sobre o assunto.

$O$ presente estudo tem por objetivo determinar as tendências da mortalidade por causas externas no periodo de 1976 a 1980, no Estado do Rio de Janeiro.

\section{METODOLOGIA}

Foram estudados todos os atestados de óbitos dos residentes do Estado do Rio de Janeiro, ou aqueles cuja ocorrência procedeu-se no referido estado e a residência era ig. norada, no período de 1976 a 1980.

Esses dados encontram-se arquivados em fitas magnéticas, cedidas ao Departamento de Epidemiologia e Métodos Quantitativos em Saúde da Escola Nacional de Saúde Pública pela Secretaria de Estado de Saúde e Higiene, como parte do convênio SESH-FIOCRUZ, para análises de mortalidade nesse período.

Para cálculo dos coeficientes de mortalidade referentes ao ano de 1980, foram utilizadas as populações de residentes por sexo e faixa etária encontradas no último cen$\mathrm{so}^{8}$. Para os outros anos, os denominadores foram estimados a partir de interpolações entre 1970 e 1980, baseando-se também nos censos do Estado do $\mathrm{Rio}^{7}$ e do antigo Estado da Guanabara em 1970, supondo-se um crescimento geométrico da população de residentes.

Algumas variáveis presentes no registro de óbito foram consideradas na análise dos dados como sexo, idade, estado civil, região de residência, local, dia e mês de ocorrência. Outras variáveis, no entanto, ainda que devendo ser preen. chidas nos registros de óbitos, não puderam ser analisadas, pela falta de informações encontrada. Para 1979, por exemplo, o percentual de óbitos por causas externas em indiví. duos com mais de 20 anos com nivel de instrução ignorado foi de $68 \%$.

As tabelas básicas foram elaboradas a partir do programa BMDP $^{5}$, utilizando-se o computador do Laboratório Nacional de Computação Científica do Conselho Nacional de Desenvolvimento Científico e Tecnológico.

Para análise da distribuição mensal dos óbitos, utilizou. se procedimento de séries temporais, isto é, o modelo de Winter.

Alguns indicadores sócio-econômicos foram construídos para todos os municípios do Estado a partir de dados do último censo ${ }^{8}$ e correlacionados com as taxas de mortalidade pelas principais causas externas. 
RESULTADOS

Mortalidade por Causas

Externas ${ }^{16,17}-1980$.

No ano de 1980, no Estado do Rio de Janeiro, a mortalidade por causas externas foi de 99 por 100.000 habitantes, uma das maiores do Brasil, ultrapassando, inclusive, a do Estado de São Paulo, de 70 por 100.000 habitantes para o mesmo ano ${ }^{6}$.

Quando comparamos com outros países, verificamos que o nosso coeficiente é dos mais altos. Para 1980, o Chile apresenta uma taxa de 78,7, o Japão de 45,3 e a Inglaterra de 41,2 . A Hungria ultrapassa esses valores, apresentando uma taxa de 114,7 por 100.000 habitantes $^{31}$.

Há que se constatar que, nos países desenvolvidos, os suicídios representam grande parte das mortes violentas, em número muito maior que os homicídios. Na Hungria e no Japão, por exemplo, a taxa de suicídio é 17 vezes maior que a taxa de homicídios. No Estado do Rio esta relação se in-verte. Para o ano de 1980, a taxa de mortalidade por lesões auto-infligidas é de 2,5 , enquanto a de homicídios é de 26,1. Além disso, a nossa taxa de mortalidade por outras violências é também muito elevada, de 32 por 100.000 habitantes (ver Tabela 1).

TABELA 1

Taxa de Mortalidade (por 100.000 Habitantes) pelas Principais Causas Externas em Alguns Paises e Estado do Rio de Janeiro - 1980

\begin{tabular}{|c|c|c|c|c|c|}
\hline \multirow[b]{2}{*}{ LOCALIDADE } & \multicolumn{5}{|c|}{ CAUSA DE ÓBITO } \\
\hline & $\begin{array}{c}\text { ACIDENTES } \\
\text { DE } \\
\text { TRÂNSITO }\end{array}$ & HOMICIDIOS & SUICIDIOS & $\begin{array}{c}\text { OUTRAS } \\
\text { VIOLÊNCIAS }\end{array}$ & $\begin{array}{l}\text { TOTAL DF: } \\
\text { CAUSAS } \\
\text { EXTERNAS }\end{array}$ \\
\hline $\begin{array}{l}\text { Chile } \\
\text { Japão } \\
\text { Inglaterra } \\
\text { Hungria } \\
\text { Est. do Rio de Janeiro }\end{array}$ & $\begin{array}{r}12,9 \\
9,9 \\
11,7 \\
16,2 \\
19,4\end{array}$ & $\begin{array}{r}2,6 \\
1,1 \\
0,8 \\
2,6 \\
26,1\end{array}$ & $\begin{array}{r}4,9 \\
17,6 \\
8.8 \\
44,9 \\
2,5\end{array}$ & $\begin{array}{r}38,1 \\
1,7 \\
3,1 \\
0,4 \\
32,0\end{array}$ & $\begin{array}{r}78,7 \\
45,3 \\
41,2 \\
114,7 \\
99,1\end{array}$ \\
\hline
\end{tabular}

$\mathrm{Na}$ tabela 2, apresentamos as taxas de mortalidade especificadas por grupos de causas e faixa etária, no Estado do Rio de Janeiro no ano de 1980. As causas externas já se consti. tuem no segundo grupo de causas de morte, ultrapassadas somente pelas doenças do aparelho circulatório.

$\mathrm{Na}$ faixa etária de $0-4$ anos, as causas externas não tèm peso significativo como fator de mortalidade, re presentando somente $10 \%$ dos óbitos por outras causas. Já nas faixas de $5-9,10-14,15-19,20-29$ e 30-39 anos, as mortes violentas constituem as primeiras causas de óbitos. A partir do grupo etário 40-49 anos, as taxas de mortalidade por doenças do aparelho circulatório e por neoplasmas ultranos 
sam as devidas às causas externas.

TABELA 2

Taxas de Mortalidade Espec/fica (por 100.000 Habitantes) por Grupo de Causas, por Faixa Etária $R J-1980$

\begin{tabular}{|c|c|c|c|c|c|c|c|c|c|c|c|}
\hline \multirow[b]{2}{*}{ DOLIC INFIC E PARASIT } & 1 & $1-4$ & $5-9$ & $10-14$ & $15-19$ & $20-29$ & $30-39$ & $40-49$ & $50-64$ & \multicolumn{2}{|c|}{$65 \mathrm{e}+\underset{\text { IDADES }}{\text { TODASAS }}$} \\
\hline & 1305,07 & 69,58 & 6,55 & 4,77 & 4,63 & 8,81 & 19,63 & 36,20 & 52,91 & 102.93 & 56,98 \\
\hline VEOPLASMAS & 10.17 & 7,64 & 7,07 & 6,18 & $\begin{array}{l}4,03 \\
7,69\end{array}$ & $\begin{array}{l}8,81 \\
9,82\end{array}$ & $\begin{array}{l}19,03 \\
29,78\end{array}$ & 105,90 & $\begin{aligned} 52,91 \\
295,08\end{aligned}$ & $\begin{array}{l}102,93 \\
849,76\end{array}$ & $\begin{array}{l}50,98 \\
90,24\end{array}$ \\
\hline D GLAND END NUTRIC TRANST IMUNIT & 481.49 & 29,65 & 2,88 & 1,33 & 1,24 & 3,67 & $\begin{array}{r}23,10 \\
7,76\end{array}$ & 20,91 & 85,70 & 332,47 & 43,01 \\
\hline D SANGLE ORG HEMATOPOETICOS & 9,80 & 1,94 & 1,13 & 1,59 & 0,50 & 1,33 & 1,26 & 1,70 & 3,21 & 11,46 & 2,21 \\
\hline TRANSTORNOS MENTAIS & - & 0,10 & - & - & 0,33 & 0,73 & 2,39 & 5,69 & 2,34 & 3,57 & 1,54 \\
\hline D SIST VERV ORG SENTIDOS & 185,74 & 15,59 & 3,58 & 4,77 & 5.46 & 4,91 & 6.03 & 6,88 & 10,41 & 23,86 & 11,84 \\
\hline D APARELHO CIRCLLLATORIO & 21,85 & 4,89 & 3,14 & 4,77 & 10,09 & 22,22 & 84,22 & 256,66 & 729,81 & 3615,44 & 291,16 \\
\hline D PPARELHO RESPIRATORIO & 1050,81 & 89,55 & 8,38 & 6,27 & 6,37 & 11,39 & 24,40 & 47,42 & 111,11 & 565,01 & 83,66 \\
\hline D APARELHO DIGESTIVO & 34.28 & 2.95 & 1.48 & 2,12 & 3,06 & 8,86 & 27,06 & 54,14 & 84,83 & 218.26 & 31.84 \\
\hline D APAR GIVITI RINARIO & 29,39 & 1.73 & 1,31 & 0,88 & 11,90 & 3,35 & 7,89 & 9,77 & 22,20 & 94,29 & 10,76 \\
\hline COMPL GRAVIDFZ PARTO PLERPERIO & - & - & - & 0,35 & 1,82 & 3,86 & 7,96 & 1,44 & 0,09 & - & 2.21 \\
\hline$D$ PELE TLC CEL SL BCLTANEO & 2,26 & - & 0,09 & 0,09 & 0,08 & 0,18 & 0.73 & 0,34 & 0,87 & 3,76 & 0.51 \\
\hline D SISTEMA OSTEOMLSC II C CONIINTIVO & $=$ & 0.10 & 0,09 & 0.35 & 0,66 & 0,78 & 1,53 & 1,27 & 2,34 & 8,26 & 1,24 \\
\hline ANOMALIAS CONCE NITAS & 350,76 & 7,13 & 2,62 & 2,12 & 1.90 & 1,06 & 0,86 & 0,76 & 0,87 & 0,56 & 10,06 \\
\hline ALG ATEC ORIG PER PERINATAL & 2150,88 & 0.41 & 0,09 & 0.18 & - & - & - & - & י וב, & - & 50,62 \\
\hline SINTOMAS SINAIS E AFICÇOF S MAL DI FIVIDAS & 197,42 & 21,80 & 3,32 & 3.53 & 7,77 & 12,26 & 20,29 & 29,66 & 57,59 & 287,39 & 36.25 \\
\hline CALSAS EXTERNAS & $271:$ & 23.53 & 25,75 & 29,68 & 91,88 & 150,12 & 129,18 & 124,42 & 109,64 & 187,09 & 99.11 \\
\hline TODAS AS CAL SAS & 5865.04 & 276,60 & 67,48 & 69,00 & 145,39 & 243,36 & 370,97 & 703,19 & 1569,00 & 6304,11 & 823.45 \\
\hline
\end{tabular}

TONTE Estatistican de Mortalidade Brasıl 1980 SNABS - Ministerio da Saúde

Analisando o Gráfico 1, observamos um pico na idade de 20 a 29 anos (de 150 por 100.000 habitantes), e verifica-se que a curva é bem diferente do tipo $U$ encontrado para to-das as causas.

\section{GRÁFICO 1}

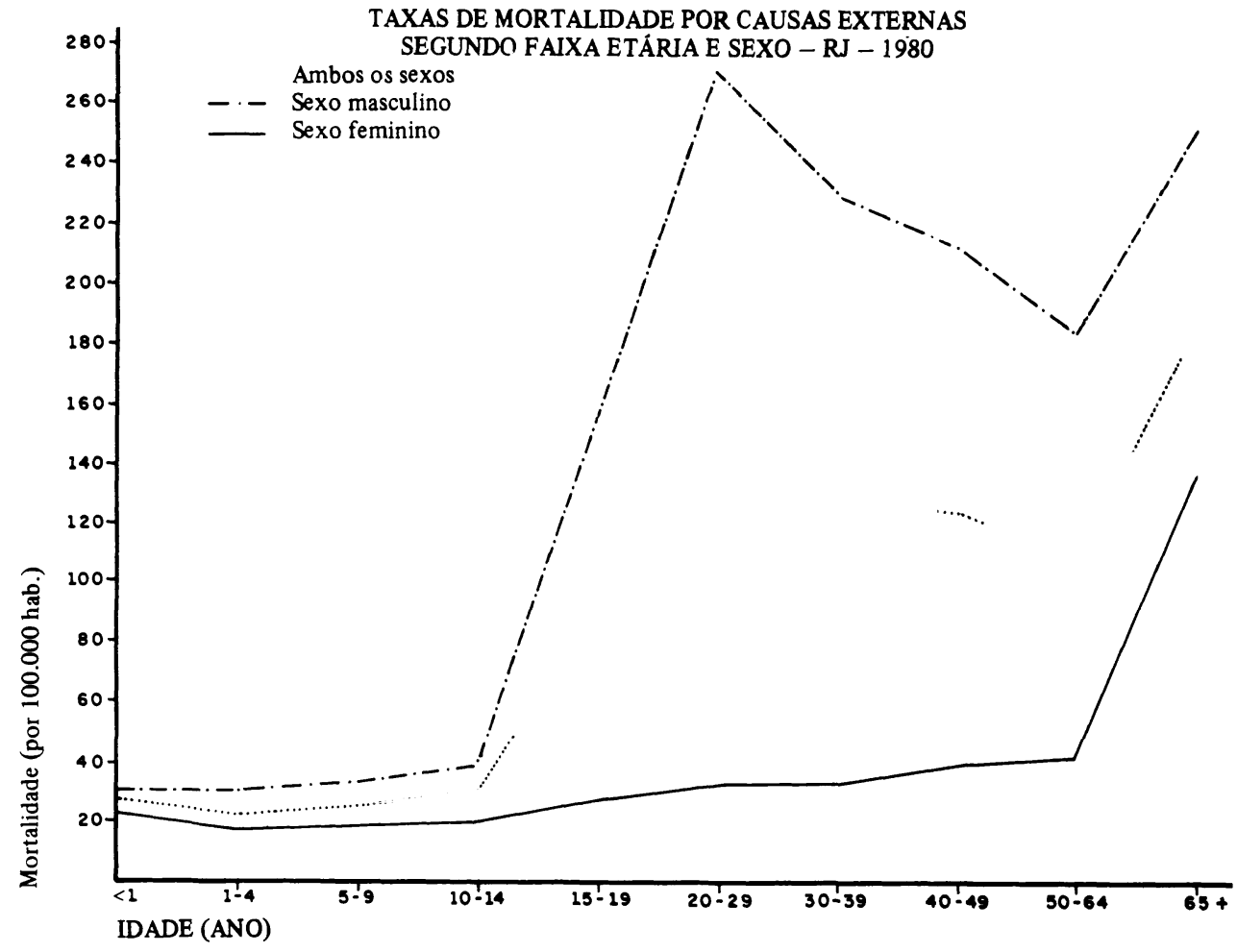


O comportamento das taxas de mortalidade por causas externas nas diversas faixas etárias não é homogêneo para os dois sexos. Enquanto que para o sexo feminino há pouca variação por faixa etária, para os homens o coeficiente se eleva e atinge valores muito grandes nos grupos de 15-19, 20-29 e 30-39 anos (Gráfico 1). Em particular, na faixa etária de 20-29 anos a taxa de homicídios calculada para o sexo masculino é 15 vezes maior que para as mulheres (ver Tabela 3). Para esta faixa etária e sexo masculino, ressalta-se que os homicídios são a principal causa de morte, ultrapassando, inclusive, todas as outras causas.

TABELA 3

Taxas de Mortalidade (por 100.000 Habitantes) Especifica por Sexo e Faixa Etária, Segundo Principais Causas Externas e Todas as Outras Causas - Rio de Janeiro, 1980

\begin{tabular}{|c|c|c|c|c|c|c|c|c|c|c|c|c|}
\hline \multirow{2}{*}{$\begin{array}{l}\text { Faixa Etária } \\
\quad(\text { ano })\end{array}$} & \multicolumn{2}{|c|}{ Ac. Trans. } & \multicolumn{2}{|c|}{ Suicídio } & \multicolumn{2}{|c|}{ Homicídio } & \multicolumn{2}{|c|}{ Les. Ignor. } & \multicolumn{2}{|c|}{ Causas Externas } & \multicolumn{2}{|c|}{ Outras Causas } \\
\hline & M & $\mathrm{F}$ & M & $\mathrm{F}$ & $\mathbf{M}$ & $\mathrm{F}$ & M & $\mathrm{F}$ & M & $\mathrm{F}$ & $\mathbf{M}$ & $\mathrm{F}$ \\
\hline $0-4$ & 5,4 & 2,6 & - & - & 0,6 & 0,5 & 14,7 & 8,6 & 30,1 & 11,9 & 1588,6 & 1284,0 \\
\hline $5-9$ & 10 & 6.2 & - & - & 0,9 & 0 & 10,9 & 8, & 32,6 & 18 & 47,6 & \\
\hline $10-14$ & 10,7 & 9,1 & 0,2 & 0,4 & 3,5 & 1,1 & 13,5 & 4,6 & 39,0 & 20 & 41,6 & 36,8 \\
\hline & & 6.9 & 1,7 & 2,1 & 58,9 & 4.1 & 49.9 & 9 & & & & \\
\hline 29 & 58,9 & 7,1 & 4,9 & 2,1 & 110,6 & 7 & 86,7 & 11,7 & 271 & 33,0 & 100,6 & \\
\hline $30-39$ & 41,8 & 7,5 & 4,1 & 3,0 & 75,3 & 4,1 & 74,5 & 13,13 & 230,9 & 33,4 & 273,0 & 211,6 \\
\hline & 48,9 & 10,4 & 5,1 & 3,3 & & 3,1 & 66,1 & 15 & & 38,7 & & 441,3 \\
\hline $50-59$ & 50,4 & 12,8 & 5,8 & 1,3 & 34,2 & 3,5 & 59,3 & 14,1 & 183,7 & 39,9 & 1584,2 & 883,3 \\
\hline 60 e + & 62,1 & 22,2 & 7,4 & 4,5 & 27,2 & 4,1 & 65,2 & 23,3 & 230,1 & 108,9 & 5454,8 & 4181,9 \\
\hline
\end{tabular}

Mortalidade por Causas

Externas - 1976 a 1980

$\mathrm{Na}$ Tabela 4 apresentamos o número absoluto de óbitos por causas externas segundo as principais causas e ano de ocorrência de 1976 a 1980 . As três principais causas externas de morte são os acidentes de trânsito de veiculo a motor (E810-E819), os homicidios (E960-E969) e as lesões que se ignora se foram acidental ou intencionalmente infligidas (E980-E989), explicando mais de 70\% de todos os óbitos por causas externas nos anos estudados. Seguemse a categoria de causas outros acidentes (E816-E829), os afogamentos (E910), as quedas acidentais (E880-E888) e os suicidios (E950-E959). As causas não referidas acima constituem menos de $10 \%$ dos óbitos por causas externas.

\section{TABELA 4}

Mortes por Causas Externas, Segundo Categorias - Estado do Rio de Janeiro. 1976 - 1980

\begin{tabular}{|c|c|c|c|c|c|c|c|c|c|c|c|c|}
\hline \multirow[b]{2}{*}{ CAUSAS DE UBITO } & \multirow{2}{*}{$\underset{1976 \cdot 1977 \cdot 1978}{\mathrm{CDD}}$} & \multirow{2}{*}{$\begin{array}{c}\text { CID } \\
1979.1980\end{array}$} & \multicolumn{2}{|c|}{1976} & \multicolumn{2}{|c|}{1977} & \multicolumn{2}{|c|}{1978} & \multicolumn{2}{|c|}{1979} & \multicolumn{2}{|c|}{1980} \\
\hline & & & N? & $\%$ & Nọ & $\%$ & N. & $\%$ & No & $\%$ & Nọ & $\%$ \\
\hline $\begin{array}{l}\text { ACIDENTES DE TRANSPORTE } \\
\text { ACIDENTES ESTRADA DE FERRO } \\
\text { ACIDENTES TRANSITO VEICULO A MOTOR }\end{array}$ & $\begin{array}{l}\text { E800-E845 } \\
\text { E800-E807 } \\
\text { E810-E819 }\end{array}$ & $\begin{array}{l}\text { E800-E848 } \\
\mathrm{E} 800-E 807 \\
\text { E810-E819 }\end{array}$ & $\begin{array}{r}3369 \\
173 \\
3163\end{array}$ & 36,73 & $\begin{array}{r}3310 \\
93 \\
3208\end{array}$ & 34,36 & $\begin{array}{r}3516 \\
99 \\
3400\end{array}$ & 33,99 & $\begin{array}{r}3466 \\
95 \\
3339\end{array}$ & 32,21 & $\begin{array}{r}2280 \\
59 \\
2193\end{array}$ & 20,37 \\
\hline $\begin{array}{l}\text { ENVENENAMENTO ACIDENTAL } \\
\text { ACIDENTES PROVOCADOS DURANTE }\end{array}$ & E850-E877 & & 75 & 0,82 & 22 & 0,23 & 18 & 0,17 & 14 & 0,13 & 12 & 0,11 \\
\hline $\begin{array}{l}\text { PROCEDDMENTO MEDICO } \\
\text { QUEDAS ACIDENTAIS } \\
\text { ACIDENTES POR FOGO E CHAMA }\end{array}$ & $\begin{array}{l}\text { E930-E936 } \\
\text { E880-E887 } \\
\text { E890-E899 }\end{array}$ & $\begin{array}{l}\text { E870-E879 } \\
\text { E880-E888 } \\
\text { E890-E899 }\end{array}$ & $\begin{array}{c}45 \\
672 \\
233\end{array}$ & $\begin{array}{l}0,70 \\
7,33 \\
2,54\end{array}$ & $\begin{array}{r}67 \\
631 \\
115\end{array}$ & $\begin{array}{l}0,70 \\
6,55 \\
1,19\end{array}$ & $\begin{array}{r}33 \\
564 \\
171\end{array}$ & $\begin{array}{l}0,32 \\
5,45 \\
1,65\end{array}$ & $\begin{array}{r}4 \\
537 \\
146\end{array}$ & $\begin{array}{l}0,04 \\
4,99 \\
1,36\end{array}$ & $\begin{array}{r}5 \\
512 \\
76\end{array}$ & $\begin{array}{l}0,04 \\
4,58 \\
0,68\end{array}$ \\
\hline
\end{tabular}

Cadernos de Saúde Pública, R.J., 2 (1):19-41.,jan/mar,1986. 


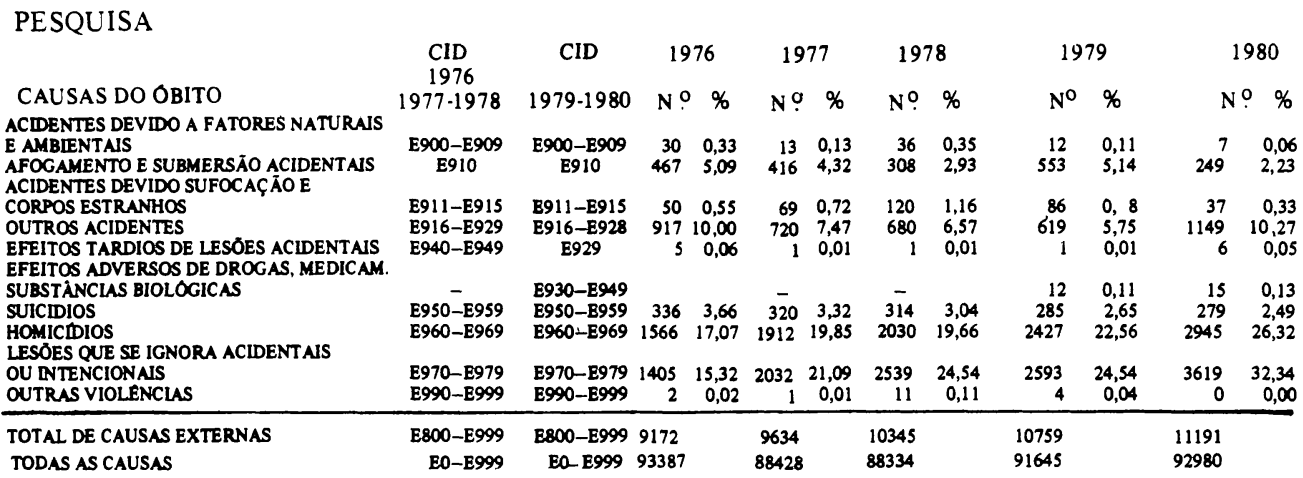

$\mathrm{Na}$ Tabela 5 apresentamos as taxas de mortalidade pelas principais causas externas e por todas as outras causas no Estado do Rio, de 1976 a 1980. Observamos que a mortalidade por todas as outras causas está em declínio, enquanto a mortalidade por causas externas vem crescendo, mostrando um aumento relativo de $11 \%$ no seu coeficiente de 1976 a 1980 . Grande aumento foi encontrado também para a taxa de homicídios. Estimou-se que, para este período, o coeficiente de mortalidade por homicídios tem uma taxa de crescimento de $14 \%$ ao ano. Os suicidios, porém, revelam uma tendência decrescente.

TABELA 5

Taxas de Mortalidade (por 100.000 Habitantes) Segundo Principais Causas Externas e por Todas as Outras Causas - Estado do Rio de Janeiro - 1976 a 1980

\begin{tabular}{lrrrrr}
\hline CAUSAS DE ÓBITO & 1976 & 1977 & 1978 & 1979 & 1980 \\
\hline ACIDENTES DE TRĀNSITO & 30,68 & 30,42 & 31,51 & 30,25 & 19.42 \\
HOMICÍDIOS & 15,19 & 18,13 & 18,85 & 21.99 & 25,08 \\
SUICÍDIOS & 3,26 & 3,03 & 2,91 & 2,58 & 2,47 \\
LESÕES QUE SE IGNORA & 13,63 & 19,27 & 23,53 & 23,49 & 32,05 \\
SE ACIDENTAIS OU INTENCIONAIS & 88,96 & 91,34 & 95,88 & 97,48 & 99.11 \\
CAUSAS EXTERNAS & 816,85 & 747,08 & 722,82 & 732,82 & 724.34 \\
OUTRAS CAUSAS & & &
\end{tabular}

Apresentamos a seguir resultados de análises mais detalhadas de mortalidade para cada uma das principais causas externas, nos anos de 1976 a 1980.

Acidentes de Trânsito

de veículos a Motor

A taxa média de mortalidade por acidentes de trânsito igual a 30 por 100.000 habitantes nos cinco anos pesquisados é elevada, quando comparada com a de outros países.

O Chile, a Inglaterra e o Japão, por exemplo, apresentam taxas em torno de 12 por 100.000 habitantes $^{31}$. A Argentina apresenta um coeficiente de 14, enquanto os Estados Unidos e a Venezuela de 24 e 37, respectivamente, para $1978^{3}$. 
De 1976 a 1979, os acidentes de trânsito de veículo a motor representaram a principal causa externa de morte, mostrando poucas oscilações para o número absoluto de óbitos, com valor médio de 3,415 nestes quatro anos. No entanto, ressalta-se que, de 1979 a 1980, houve um declí. nio no número de mortes por acidentes de trânsito de veículo a motor, correspondendo a mais de 1.000 óbitos (ver tabela 4).

Por outro lado, a categoria de causas lesões que se ignora se acidental ou intencionalmente infligidas mostrou um aumento de cerca de 1.000 óbitos neste mesmo período (ver tabela 4). Hipotetiza-se, assim, que o decréscimo re. pentino no número de acidentes de trânsito fatais não se constitui numa verdadeira diminuição dos óbitos por esta causa: apenas eles estariam sendo classificados sob outra rubrica, a das lesões ignoradas se acidentais ou intencionais.

A tabela 6 mostra que, de 1976 a 1980, os atropelamentos constituíram o principal tipo de acidente, representando $51 \%$ destes óbitos.

\section{TABELA 6}

Óbitos por Acidentes de Trânsito Segundo Tipo de Acidentes - Estado do Rio de Janeiro. 1976 - 1980

\begin{tabular}{|c|c|c|c|c|c|c|c|c|c|c|}
\hline \multirow{2}{*}{ CAUSAS DE OBITO } & \multicolumn{2}{|c|}{1976} & \multicolumn{2}{|c|}{1977} & \multicolumn{2}{|c|}{1978} & \multicolumn{2}{|c|}{1979} & \multicolumn{2}{|c|}{1980} \\
\hline & No & $\%$ & № & $\%$ & No & $\%$ & $\mathrm{~N}^{\circ}$ & $\%$ & № & $\%$ \\
\hline $\begin{array}{l}\text { COLISÃO ENTRE } 2 \\
\text { OU MAIS VEICULOS } \\
\text { ATROPELAMENTOS } \\
\text { DE NATUREZA }\end{array}$ & $\begin{array}{r}417 \\
1834\end{array}$ & $\begin{array}{l}13,2 \\
58,0\end{array}$ & $\begin{array}{r}200 \\
1701\end{array}$ & $\begin{array}{r}6.2 \\
53.0\end{array}$ & $\begin{array}{r}17 \\
1585\end{array}$ & $\begin{array}{r}0.5 \\
46.6\end{array}$ & $\begin{array}{c}7 \\
1607\end{array}$ & $\begin{array}{r}0,2 \\
48,1\end{array}$ & $\begin{array}{r}7 \\
1128\end{array}$ & $\begin{array}{r}0,3 \\
51.5\end{array}$ \\
\hline $\begin{array}{l}\text { NÃO ESPECIFICADA } \\
\text { OUTROS ACIDENTES }\end{array}$ & $\begin{array}{r}881 \\
31\end{array}$ & $\begin{array}{r}27,9 \\
0,9\end{array}$ & $\begin{array}{r}1268 \\
39\end{array}$ & $\begin{array}{r}39,6 \\
1.2\end{array}$ & $\begin{array}{r}1781 \\
17\end{array}$ & $\begin{array}{r}52,4 \\
0,5\end{array}$ & $\begin{array}{r}1695 \\
30\end{array}$ & $\begin{array}{r}50,8 \\
0,9\end{array}$ & $\begin{array}{r}1036 \\
22\end{array}$ & $\begin{array}{r}47,2 \\
1,0\end{array}$ \\
\hline $\begin{array}{l}\text { TOTAL DE: ACIDENTES } \\
\text { DE TRĀNSITO }\end{array}$ & 3163 & & 3208 & & 3400 & & 3339 & & 2193 & \\
\hline
\end{tabular}

Além desta especificação, se houve ou não atropelamento, poucas informações sobre a forma de ocorrência dos acidentes de trânsito podem ser estabelecidas nas estatísticas de mortalidade. Como se observa na Tabela 6, a maioria dos outros acidentes de trànsito são classificados como S.O.E. (sem outras especificações).

O quarto dígito nas causas de morte por acidentes ${ }^{17,18}$ de trânsito de veículo a motor nos dá informações sobre a condição do indivíduo lesado (os algarismos 0,1 e 2 indicam, respectivamente, condutor, passageiro e motociclista, enquanto o 9 representa ignorado ${ }^{17,18}$. No nosso levantamento das causas de morte por acidentes de trânsito de veiculo a motor, incluindo-se o 4 9 d ́igito da rubrica, encontramos grandes concentrações de 9 para último algarismo. 
Homicidios, Suicidios e

Lesões Ignoradas se Acidental

ou Intencionalmente Infligidas

O número absoluto de mortes violentas cresceu de cerca de 2.000 óbitos de 1976 a 1980 . Contribuiu para isto o elevado número de homicídios, representando, em 1980, 26\% do total de óbitos por causas externas (Tabela 4).

Já as taxas de mortalidade por suicidios, além de baixas, vêm decrescendo de 1976 a 1980 , de 3,26 para 2,47 por 100.000 habitantes (Tabela 5). Apesar de ser fato conhecido que os óbitos por suicídios são subnotificados e classificados como outras causas externas, a tendência de declínio é nitida.

A Tabela 4 evidencia também o grande número de óbitos classificados como lesões que se ignora se foram acidental ou intencionalmente infligidas. Esta categoria é a primeira causa externa de morte para o ano de 1980, tendo sido classificadas sob esta rubrica $32 \%$ das mortes por causas externas. Esse percentual, de 1976 a 1980, dobrou de magnitude.

Na Tabela 7, encontram-se os homicídios, os suicídios e as lesões ignoradas se acidental ou intencionais, distribuidos segundo o meio utilizado.

TABELA 7

Mortes Violentas, Segundo as Principais Cauras Especificadas por Meio Utilizado - Estado do Rio de Janeiro. 1976 a 1980

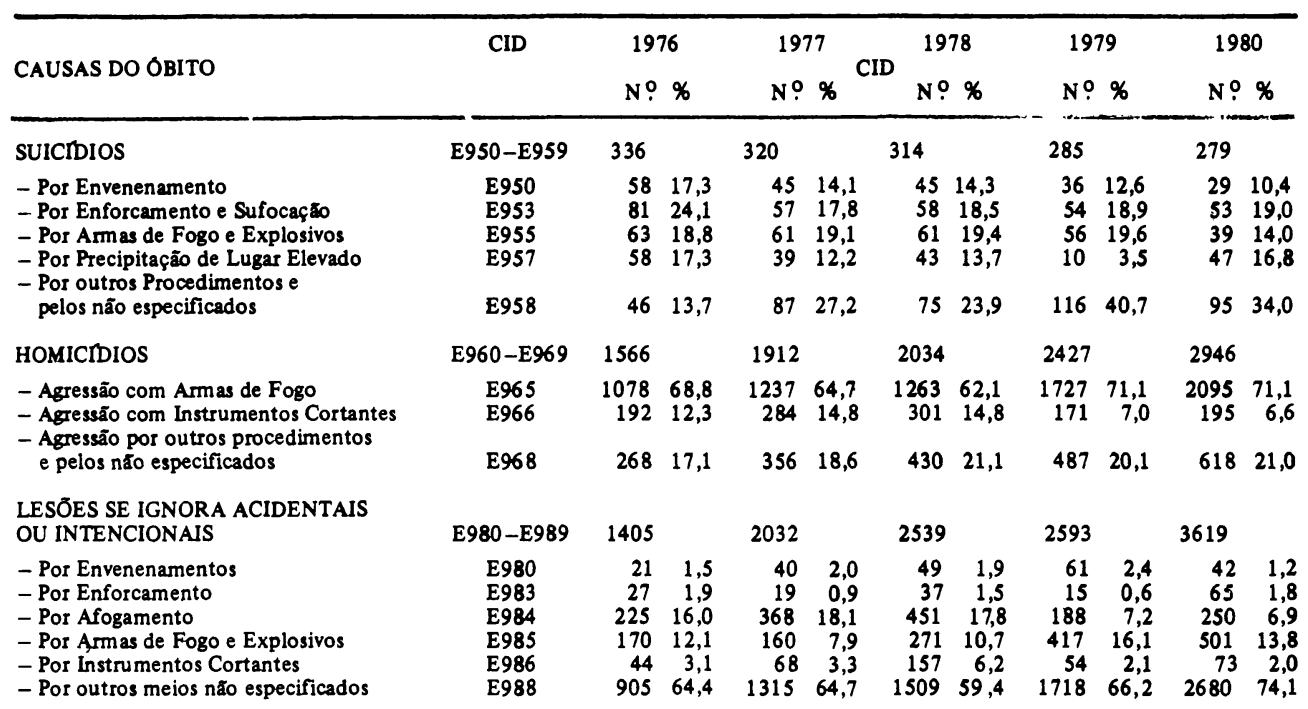

Observamos que a maior parte dos homicídios foi praticada com armas de fogo em todos os anos estudados. Em 76,77 e 78 , estes representaram $80 \%$ dos homicídios por procedimentos especificados, enquanto que, em 79 e 80 , 
esse percentual aumentou para $90 \%$. Os instrumentos cortantes foram o segundo meio utilizado, representando, porém, um percentual pequeno, de somente $8 \%$ em 1980.

Analisando os procedimentos usados para a prática dos suicídios, encontramos proporções que não diferem muito entre si para os envenenamentos, enforcamentos, armas de fogo e precipitação de lugar elevado. Em alguns anos o meio mais utilizado foi o enforcamento, enquanto que em outros foi o uso de armas de fogo.

Das lesões que se ignora se foram acidentais ou intencionais das quais se conhece o meio como foram infligidas, a maior parte delas foi armas de fogo, em 1979 e 1980. Nos anos anteriores, ocorreram muitas por afogamento.

No ano de 1980, em 2680 mortes (24\% de todos os óbtos por causas externas), além de se ignorar se a lesão foi causada acidental ou intencionalmente, ignora-se também o meio utilizado.

Nesse último ano, entre os homicídios, suicídios e lesões ignoradas dos quais se conhece o meio como foram infligidos, $76 \%$ foram praticados com armas de fogo.

\section{Outros Acidentes, Afogamentos e}

Quedas Acidentais

$\mathrm{Na}$ tabela 4 em percentual relativamente elevado, cerca de $10 \%$, encontra-se a categoria de óbitos outros acidentes. Esta categoria abrange grande número de óbitos, pois inclui os acidentes sem outras especificações (E928-9), como se pode observar na Tabela 8.

TABELA 8

Obitos por Quedas Acidentais e Outros Acidentes Estado do Rio de Janeiro. 1976 a 1980

\begin{tabular}{|c|c|c|c|c|c|c|c|c|c|c|c|c|}
\hline \multirow{2}{*}{ CAUSAS DO ÓBITO } & \multirow{2}{*}{$\begin{array}{c}\text { CID } \\
1976 \\
1977-1978\end{array}$} & \multirow{2}{*}{$\begin{array}{c}\text { CID } \\
1979-1980\end{array}$} & \multicolumn{2}{|c|}{1976} & \multicolumn{2}{|c|}{1977} & \multicolumn{2}{|c|}{1978} & \multicolumn{2}{|c|}{1979} & \multicolumn{2}{|c|}{1980} \\
\hline & & & N? & $\%$ & $\mathrm{~N}^{\circ}$ & $\%$ & No & $\%$ & No & $\%$ & No? & $\%$ \\
\hline QUEDAS ACIDENTAIS & $\mathrm{E} 880-\mathrm{E} 887$ & F. $880-E 888$ & 672 & & 631 & & 564 & & 537 & & 512 & \\
\hline $\begin{array}{l}\text { Fratura de Causa } \\
\text { não especificada }\end{array}$ & E887 & E887 & 648 & 96,4 & 610 & 96,7 & 554 & 98,2 & 229 & 42,6 & 294 & 57,4 \\
\hline $\begin{array}{l}\text { Outras quedas, } \\
\text { ou não especticadas }\end{array}$ & E887 & E888 & - & & - & & - & & 297 & 55,3 & 206 & 40,2 \\
\hline OUTROS ACIDENTES & E916-E929 & E916-E928 & 917 & & 720 & & 680 & & 619 & & 1149 & \\
\hline Acidentes não especificados & E929 & E928.9 & 777 & 84,7 & 586 & 81,4 & 538 & 79,1 & 520 & 84,0 & 1047 & $91,1^{m}$ \\
\hline
\end{tabular}


Destacam-se, ainda, na Tabela 4, os afogamentos que em média representam $4 \%$ dos óbitos por causas externas, e as quedas acidentais $(6 \%)$, que se mostram bastante importantes nos indivíduos mais idosos. No entanto, observamos que, nos anos de 1979 e 1980, após a subdivisão nas rubricas E887, E888, 43\% e 57\%, respectivamente, das quedas acidentais são fraturas de causa não especificada, podendo efetivamente não serem conseqüentes a quedas.

Estudo da Mortalidade por Causas Externas segundo principais causas, faixa etária, sexo, local, região e dia da semana de ocorrência - ano de 1979

Apresentamos nesta seção uma análise da mortalidade por causas externas segundo alguns fatores para o ano de 1979. O ano de 1980 não foi escolhido, pois o percentual de óbitos classificados como lesões ignoradas se acidental ou intencionalmente infligidas foi muito grande neste ano.

$\mathrm{Na}$ Tabela 9, apresentamos o número de obitos e a mortalidade proporcional pelas principais causas externas segundo sexo e faixa etária, no ano de 1979.

\section{TABELA 9}

Mortalidade Proporcional, Segundo Principais Causas Externas, Sexo e Faixa Ettária Estado do Rio de Janeiro - 1979

\begin{tabular}{|c|c|c|c|c|c|c|c|c|c|c|c|c|c|c|c|c|c|c|}
\hline \multirow{3}{*}{ CAUSAS DE OBITO } & \multicolumn{6}{|c|}{ FANXA ETARIA (ANO) } & & & & & & & & & & & & \\
\hline & \multicolumn{2}{|c|}{04} & \multicolumn{2}{|c|}{5.9} & \multicolumn{2}{|c|}{10.14} & \multicolumn{2}{|c|}{15.19} & \multicolumn{2}{|c|}{$20-29$} & \multicolumn{2}{|c|}{$30-39$} & \multicolumn{2}{|c|}{$40-49$} & \multicolumn{2}{|c|}{50.59} & \multicolumn{2}{|c|}{$\Leftrightarrow 3 \mathrm{e}^{+}$} \\
\hline & $M$ & $\mathbf{F}$ & M & $\mathbf{F}$ & M & $\mathrm{F}$ & M & $\mathbf{F}$ & M & $\mathbf{F}$ & M & $\mathrm{F}$ & M & $\mathrm{F}$ & $M$ & F & 14 & $F$ \\
\hline $\begin{array}{l}\text { Atropelamentus (E81t) } \\
\text { At Ac Tras Ves Motor }\end{array}$ & 1.6 & 0.5 & 9.1 & 10,0 & 12,9 & 7.9 & 6.2 & 4.0 & 6.2 & 3.2 & 6.1 & 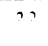 & 3.9 & 1.9 & 12.1 & 10 & 11 & 06 \\
\hline (E810-E819 exuito E814) & 1.6 & 1.2 & 7.2 & 6.6 & 6.2 & 8.3 & 8,1 & 8.4 & 10.9 & 6.1 & 7.3 & 2.7 & 4.0 & $1.7^{\circ}$ & 17 & 1.1 & 0.7 & 0.2 \\
\hline Quedas Acidentais (E889-E887) & 0.8 & 0.5 & 1.3 & 0.8 & 1,4 & 1.0 & 1.1 & 0.0 & 1.1 & 0,2 & 1.3 & 04 & 1.0 & 0.2 & 06 & 25 & 0.5 & 09 \\
\hline Afogamentos (E910) & 2.1 & 0.8 & 4.3 & 2,8 & 6,9 & 3.3 & 8.7 & 1.1 & 3.9 & 0.8 & 1.6 & 0.1 & 0.9 & 0.1 & 0.3 & ii & 0.1 & 03 \\
\hline Outros Acidentes (E916 - E929) & $\ddot{00}$ & 4.1 & 2.8 & 2,3 & 4.6 & 2.0 & 3,3 & 2,5 & 3.2 & 1.8 & 2.8 & 0.7 & 1.4 & 0.1 & 0.8 & 0.4 & 2.6 & 0.1 \\
\hline Sulidios (E950-E959) & - & & & & - & 1.1 & 1.0 & 2.5 & 1.3 & 2.3 & 0.9 & 1.0 & 0.5 & 0.5 & 0.3 & 03 & is & 01 \\
\hline Homicidios (E960-E969) & 0.2 & 0.1 & 0.2 & 0,3 & 3.4 & 4.0 & 22.5 & 5.7 & 26.0 & 2.9 & 14.2 & 2.3 & 4.6 & 0.7 & 18 & 0.3 & 0.4 & 0.3 \\
\hline (E980-E989) & 2.8 & $\therefore h$ & 89 & 6.8 & 12.1 & 6.7 & 19.8 & 103 & 16.8 & 9.2 & 10.9 & 4.1 & 0.5 & 2.1 & $\ldots$ & 03 & 09 & 03 \\
\hline $\begin{array}{l}\text { Total de Causas Externas } \\
\text { (E800-E999) }\end{array}$ & 107 & 77 & 372 & 33.3 & 49.8 & 35.8 & 72.4 & 36.5 & 71.2 & 28.4 & 46.5 & 149 & 223 & 79 & $10:$ & 50 & +1 & $2 \pm$ \\
\hline Outras Causas It $0-E 799$; & 893 & 923 & 62.8 & 66.7 & 50.2 & 64.2 & 27.6 & 63.5 & 28.8 & 71.6 & 53.5 & 85.1 & 777 & 92.1 & 898 & 950 & 959 & 97.6 \\
\hline
\end{tabular}

Os atropelamentos a crianças em idade escolar, na faixa de 5--14 anos, mostram-se de real gravidade, constituindo a primeira causa de óbito e representando $26 \%$ do total de óbitos. Neste grupo, destaca-se também o grande número de afogamentos.

Entre 15-19 anos, cresce ainda mais o percentual de óbitos devidos às causas externas $(61 \%$ do total de óbitos neste grupo). Entre os homens, o homicídio é o principal fa. tor de mortalidade, enquanto entre as mulheres são os acidentes de trânsito de veículo a motor. 
Para os homens de 20-29 anos, a violência, sobretudo o homicidı, atinge seu percentual máximo. Em relação às mulheres nesta mesma faixa de idade, o comportamento da mortalidade é bem diferente, permanecendo ainda os ac1dentes de trànsito como a principal causa externa.

$\mathrm{Na}$ faixa de 30-39 anos, o percentual de mortes violentas decresce, particularmente entre as mulheres. As princ:pais causas externas continuam sendo os homicídios para o sexo masculino e os acidentes de trânsito para o feminino.

A partir dos 40 anos. as causas externas se mostram bem menos significativas. Nas faixas etárias de 40-49 e 50-59 anos. para ambos os sexos, os dados revelam os acidentes de de trânsito como a principal causa externa e, entre eles. os atropelamentos que voltam a ter grande peso. Para os mais idosos, individuos com mais de 60 anos, as quedas aciden. tals mostram-se relevantes, principalmente entre as mulheres.

$\mathrm{Na}$ Tabela 10, apresentamos a distribuição dos óbitos ocorridos em 1979 segundo as principars causas externas. local - hospital. via pública. domicilio ou outro - e região de ocorrência. O Estado do Rıo de Janerro for subdividido em très regiões: a primeira, formada pelo Municíplo do Rio de Janeiro, a capital do estado; a segunda. o Grande Rio. conforme denominaçao do IBGE, constituida dos munıcipıos da área metropolitana do estado, exclundo a capital: e a terceira. o Interior, formada pelos demais municíplos.

TABELA 10

Ointos. Scgundo Algumas Causas Extcrnas. Local e Regläo de Ocorrencia - R.J - 19-4

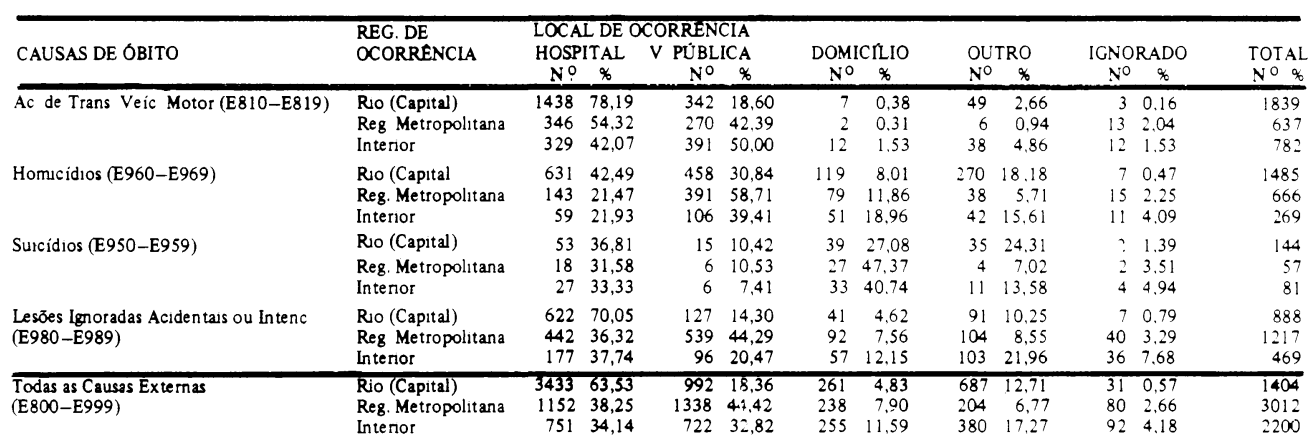

Observamos na Tabela 10 que a proporção de mortes por acidentes de trânsito ocorridas en hospitais da capital ( 78. $16 \%)$ é mais do que quatro vezes maior que a proporção dos óbitos ocorridos em via pública $(18.60 \%)$. Na região do Grande Rio, essa razão é de $1.3(54.32 \%: 42.39 \%)$ e no Interior de $0,84 \%(42,07 \%: 50,00 \%)$.

Para os homicídios e as lesões ignoradas, essa diferença se acentua. Fora da capital, o número de óbitos ocorridos na 
via pública ultrapassa em muitos os que aconteceram no hospital. Esses dados revelam a maior capacidade de socorro imediato no Município do Rio, quando comparado com as outras regiões do estado.

$\dot{E}$ interessante observar que os homicidios ocorrem com freqüências acentuadas nos domicílios, principalmente no interior do estado. Evidenciamos também as proporções não baixas de homicidios na categoria outro, que devem representar, na grande maioria dos casos, as penitenciárias.

Quanto aos suicidios, observamos que eles são muito fre. qüentes nos domicílios em todas as três regiões.

$\mathrm{Na}$ Tabela 11, mostramos que as mortes devidas às cau. sas externas ocorrem com maior freqüência nos fins-desemana. Aquelas que aconteceram na via pública demons. tram maior ocorrência aos sábados e domingos e os óbitos hospitalares ocorrem com maior proporção nos fins-desemana e na 2 a feira.

TABELA 11

Distribuição dos Obitos, Segundo Algumes Causes Externas, Local e Dia da Semana de Ocorrencia - RJ - 1979

\begin{tabular}{|c|c|c|c|c|c|c|c|c|c|c|c|c|c|c|c|c|}
\hline \multirow[t]{2}{*}{ CAUSAS DE OBITO } & \multirow[t]{2}{*}{$\begin{array}{l}\text { LOCAL DE } \\
\text { OCORRENCIA }\end{array}$} & \multicolumn{4}{|c|}{ DIA DA SEMANA } & \multicolumn{2}{|c|}{$4^{a}$ feira } & \multicolumn{2}{|c|}{$5^{\mathrm{a}}$ feira } & \multicolumn{2}{|c|}{$6^{\mathrm{a}}$ feira } & \multicolumn{2}{|c|}{ Sábado } & \multirow[t]{2}{*}{ Domingo } & \multirow[t]{2}{*}{ Ignorado } & \multirow[t]{2}{*}{ Total } \\
\hline & & $\mathrm{N}^{\circ}$ & $0 \%$ & $\mathbf{N}$ & $0 \%$ & $\mathrm{~N}^{\circ}$ & $\%$ & No & $\%$ & $N^{O}$ & $\%$ & No & $\%$ & & & \\
\hline $\begin{array}{l}\text { Atropeiamentos } \\
\text { (E814) }\end{array}$ & $\begin{array}{l}\text { Via Pública } \\
\text { Hospital }\end{array}$ & $\begin{array}{l}25 \\
97\end{array}$ & $\begin{array}{l}13.6 \\
19.6\end{array}$ & $\begin{array}{l}14 \\
55\end{array}$ & $\begin{array}{r}7.6 \\
11.1\end{array}$ & $\begin{array}{l}19 \\
62\end{array}$ & $\begin{array}{l}10.3 \\
12.5\end{array}$ & $\begin{array}{l}20 \\
52\end{array}$ & $\begin{array}{l}10.9 \\
10,5\end{array}$ & $\begin{array}{l}19 \\
66\end{array}$ & $\begin{array}{l}10,3 \\
13.3\end{array}$ & $\begin{array}{l}50 \\
67\end{array}$ & $\begin{array}{l}27,2 \\
13,5\end{array}$ & $\begin{array}{ll}37 & 20.1 \\
97 & 19.5\end{array}$ & $\begin{array}{l}190 \\
685\end{array}$ & $\begin{array}{r}374 \\
1181\end{array}$ \\
\hline $\begin{array}{l}\text { Ot Acid Trans Veic Motor } \\
\text { (E810-E819), exceto E814) }\end{array}$ & $\begin{array}{l}\text { Via Publica } \\
\text { Hospital }\end{array}$ & $\begin{array}{l}47 \\
78\end{array}$ & $\begin{array}{l}12.9 \\
17.0\end{array}$ & $\begin{array}{l}51 \\
60\end{array}$ & $\begin{array}{l}14,1 \\
13.1\end{array}$ & $\begin{array}{l}44 \\
44\end{array}$ & $\begin{array}{r}12.1 \\
9.6\end{array}$ & $\begin{array}{l}40 \\
49\end{array}$ & $\begin{array}{l}11.0 \\
10,7\end{array}$ & $\begin{array}{l}48 \\
42\end{array}$ & $\begin{array}{r}13,2 \\
9,2\end{array}$ & $\begin{array}{l}71 \\
89\end{array}$ & $\begin{array}{l}19.6 \\
19.4\end{array}$ & $\begin{array}{ll}62 & 17,1 \\
96 & 21,0\end{array}$ & $\begin{array}{l}313 \\
498\end{array}$ & $\begin{array}{l}676 \\
956\end{array}$ \\
\hline $\begin{array}{l}\text { Homicidios } \\
\text { (E960-E969) }\end{array}$ & $\begin{array}{l}\text { Via Pública } \\
\text { Hospital }\end{array}$ & $\begin{array}{l}43 \\
48\end{array}$ & $\begin{array}{r}9.8 \\
13,2\end{array}$ & $\begin{array}{l}45 \\
39\end{array}$ & $\begin{array}{l}10,2 \\
10,7\end{array}$ & $\begin{array}{l}48 \\
35\end{array}$ & $\begin{array}{r}10,9 \\
9,6\end{array}$ & $\begin{array}{l}45 \\
44\end{array}$ & $\begin{array}{l}10,2 \\
12,1\end{array}$ & $\begin{array}{l}72 \\
44\end{array}$ & $\begin{array}{l}16,3 \\
12,1\end{array}$ & $\begin{array}{l}87 \\
72\end{array}$ & $\begin{array}{l}19,7 \\
19,8\end{array}$ & $\begin{array}{rr}101 & 22,9 \\
81 & 22.3\end{array}$ & $\begin{array}{l}515 \\
474\end{array}$ & $\begin{array}{l}956 \\
837\end{array}$ \\
\hline $\begin{array}{l}\text { Lesóes Ignor. Acid ou Intenc } \\
\text { (E980-E989) }\end{array}$ & $\begin{array}{l}\text { Via Pública } \\
\text { Hospital }\end{array}$ & $\begin{array}{r}63 \\
101\end{array}$ & $\begin{array}{l}12,6 \\
14,6\end{array}$ & $\begin{array}{l}78 \\
98\end{array}$ & $\begin{array}{l}15,6 \\
14,2\end{array}$ & $\begin{array}{l}65 \\
82\end{array}$ & $\begin{array}{l}13,0 \\
11,8\end{array}$ & $\begin{array}{l}66 \\
89\end{array}$ & $\begin{array}{l}13,2 \\
12,9\end{array}$ & $\begin{array}{l}54 \\
87\end{array}$ & $\begin{array}{l}10,8 \\
12,6\end{array}$ & $\begin{array}{r}87 \\
120\end{array}$ & $\begin{array}{l}17,3 \\
17,3\end{array}$ & $\begin{array}{rr}88 & 17,5 \\
115 & 16,6\end{array}$ & $\begin{array}{l}267 \\
559\end{array}$ & $\begin{array}{r}768 \\
1251\end{array}$ \\
\hline Todas as Causes & Via Pública & 204 & 12,2 & 214 & 12,8 & 193 & 11,6 & 193 & 11,6 & 213 & 12.8 & 325 & 19,5 & $326 \quad 19,5$ & 1441 & 3109 \\
\hline Externas (E800-E999) & Hospital & 403 & 15.6 & 330 & 12,8 & 314 & 12,1 & 328 & 12.7 & 318 & 12,3 & 421 & 16,3 & $472 \quad 18.3$ & 2800 & 5386 \\
\hline
\end{tabular}

Estudo da Distribuição

Mensal das Principais

Causas Externas - 1976 a 1980.

Distribuição Mensal dos Homicídios

Para estudar a distribuição mensal dos homicídios e verificar alguma sazonalidade, foi construído o gráfico com acompanhamento do número de homicídios ocorridos mês a mês, de 1976 a 1980 (Gráfico 2).

Pela análise deste gráfico, dois fatores ficam nítidos: a tendência crescente em torno de uma reta e picos periódi. cos nos primeiros meses de cada ano. Nota-se, também, que as amplitudes da série crescem conjuntamente com o núme. ro médio de homicídios por ano.

Tendo em vista as observações feitas no Gráfico 2, decidiu-se analisar a série temporal da distribuição mensal dos homicídios através do método de Winter ${ }^{2}{ }^{3}$. 
GRÁFICO 2

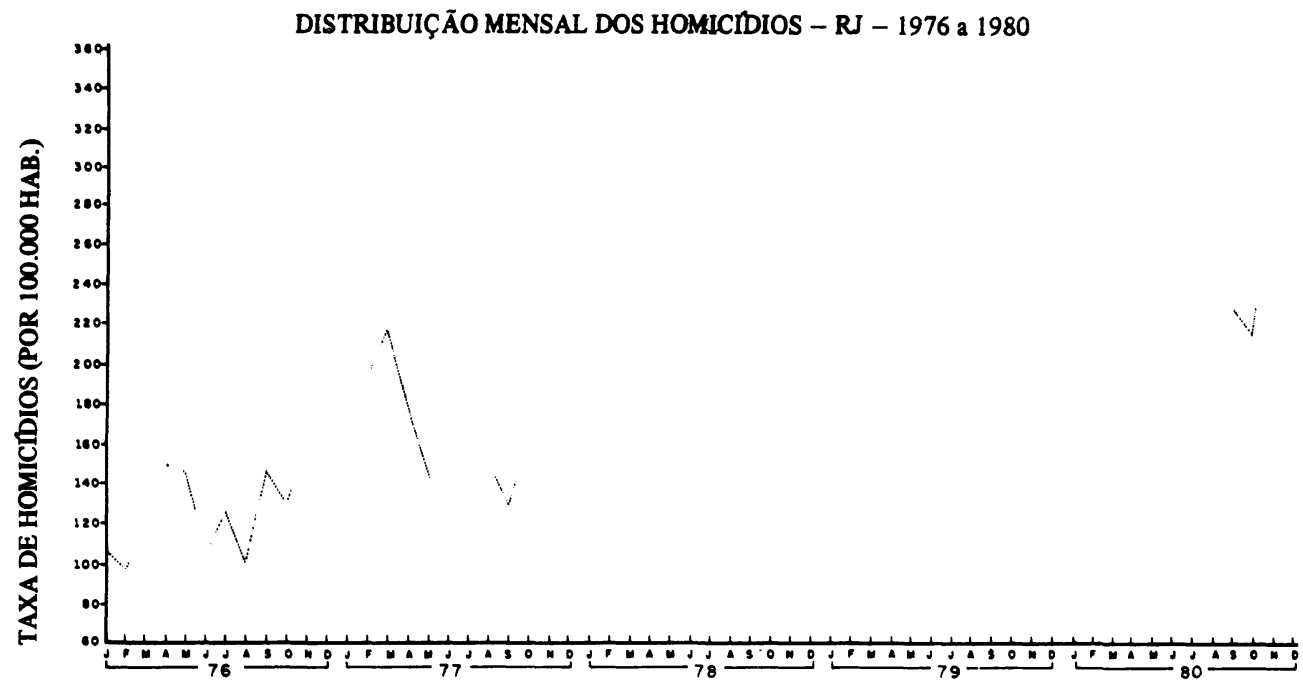

Supós-se, então, que a série temporal é adequadamente representada pelo modelo multiplicativo:

$$
\begin{aligned}
& x_{t}=\left(b_{1}+b_{2} t\right) c_{t}+e_{t}, \text { onde } \\
& 12 \\
& \Sigma c_{t}+12, b_{1} \text { é componente permanente, } b_{2} \\
& t=1
\end{aligned}
$$

é componente de tendência linear e $c_{t}$ é o fator multiplicativo de sazonalidade.

Através de um procedimento interativo, obtiveram-se os valores dos parâmetros do modelo para cada mès, utilizando-se os dados dos quatro primeiros anos para inicialização do modelo e o último ano para previsão. Os resultados en-

\begin{tabular}{|c|c|c|c|c|c|c|}
\hline \multirow{2}{*}{ PERIODO } & \multicolumn{5}{|c|}{ RESULTADO DA FASE DE INICIALIZAÇĀO } & \multirow[b]{2}{*}{ RESIDUO } \\
\hline & OBSERVAÇÃO & $\begin{array}{l}\text { COMPONENTE } \\
\text { PERMANENTE }\end{array}$ & TENDENCIA & $\begin{array}{c}\text { FATOR } \\
\text { SAZONAL }\end{array}$ & $\begin{array}{l}\text { MODELO } \\
\text { AJUSTADO }\end{array}$ & \\
\hline $\begin{array}{l}1 \mathrm{Jan} . \\
2 \mathrm{Fev} . \\
3 \mathrm{Mar} . \\
4 \mathrm{Abr} . \\
5 \mathrm{Mai} . \\
6 \mathrm{Jun} . \\
7 \mathrm{Jul} . \\
8 \mathrm{Ago} .\end{array}$ & $\begin{array}{c}106,0000 \\
95,0000 \\
123,0000 \\
150,0000 \\
147,0000 \\
103,0000 \\
126,0000 \\
100,0000\end{array}$ & $\begin{array}{l}117,2488 \\
113,7482 \\
113,6076 \\
118,0414 \\
123,8187 \\
125,5192 \\
129,3249 \\
127,8568\end{array}$ & $\begin{array}{l}1,6617 \\
1,1455 \\
1,0168 \\
1,3585 \\
1,8004 \\
1,7904 \\
1,9920 \\
1,6459\end{array}$ & $\begin{array}{l}1,0409 \\
1,0809 \\
1,1458 \\
1,1185 \\
1,0175 \\
0,8238 \\
0,9071 \\
0,9025\end{array}$ & $\begin{array}{c}0,0 \\
133,6931 \\
132,9192 \\
125,1316 \\
117,9093 \\
103,5489 \\
113,9721 \\
121,3090\end{array}$ & $\begin{array}{r}0,0 \\
-38,6931 \\
-9,9192 \\
24,8684 \\
29,0907 \\
-\quad 0,5489 \\
12,0279 \\
-21,3090\end{array}$ \\
\hline
\end{tabular}
contram-se na Tabela 12.

\section{TABELA 12}

Resultados do Ajuste da Série Temporal dos Óbitos por Homicidios, Segundo Modelo Winter. 

PERIODO OBSIRVAÇÃO COMPONENTE TENDFNCIA FATOR MODELO RESIDUO
PIEMANINTI:

\begin{tabular}{|c|c|c|c|c|c|c|}
\hline 9 Set. & 147,0000 & 134,7422 & 2,1699 & 0,9235 & 115,7735 & 31,2265 \\
\hline 10 Out. & 131,0000 & 137,4034 & 2,2190 & 0,9373 & 127,9386 & 3,0614 \\
\hline 11 Nov. & 159,0000 & 143,1381 & 2,5706 & 0,9955 & 136,1461 & 22,8339 \\
\hline $12 \mathrm{Dez}$. & 176,0000 & 147,2643 & 2,7261 & 1,1378 & 164,3050 & 11,6950 \\
\hline $13 \mathrm{Jan}$. & 170,0000 & 151,9888 & 2,9260 & 1,0526 & 156,1324 & 13,8676 \\
\hline $14 \mathrm{Fev}$. & 195,0000 & 158,7371 & 3,3082 & 1,1031 & 167,4544 & 27,5456 \\
\hline $15 \mathrm{Mar}$. & 217,0000 & 166,1477 & 3,7185 & 1,1698 & 185,6644 & 31,3356 \\
\hline $16 \mathrm{Abr}$. & 177,0000 & 168,1228 & 3,5441 & 1,1087 & 189,9998 & $-12,9998$ \\
\hline $17 \mathrm{Mal}$. & 144,0000 & 167,1460 & 3,0920 & 0,9941 & 174,6660 & $-30,6660$ \\
\hline 18 Jun. & 126,0000 & 167,6461 & 2,8328 & 0,8129 & 140,2337 & $-14,2337$ \\
\hline $19 \mathrm{Jul}$. & 136,0000 & 167,3965 & 2,5246 & 0,8929 & 154,6404 & $-18,6404$ \\
\hline $20 \mathrm{Ago}$. & 152,0000 & 169,6950 & 2,5020 & 0,9015 & 153,3604 & $-1,3604$ \\
\hline 21 Set. & 128,0000 & 167,1571 & 1,9980 & 0,8999 & 159,0296 & $-31,0196$ \\
\hline 22 Out. & 159,0000 & 169,2273 & 2,0052 & 0,9376 & 158,5488 & 0,4512 \\
\hline 23 Nov. & 139,0000 & 166,4927 & 1,5312 & 0,9714 & 170,4548 & $-31,4548$ \\
\hline 24 Dez. & 160,0000 & 163,9145 & 1,1203 & 1,1135 & 191,1696 & $-31,1696$ \\
\hline $25 \mathrm{Jan}$. & 187,0000 & 166,9283 & 1,3096 & 1,0627 & 173,7126 & 13,2874 \\
\hline $26 \mathrm{Fev}$. & 180,0000 & 167,4794 & 1,2338 & 1,0988 & 185,5783 & $\begin{array}{r}-5,5783 \\
-\end{array}$ \\
\hline 27 Mar. & 180,0000 & 166,4870 & 1,0112 & 1,1565 & 197,3609 & $-17,3609$ \\
\hline $28 \mathrm{Abr}$. & 180,0000 & 166,7270 & 0,9340 & 1,1043 & 185,6997 & $-5,6997$ \\
\hline 29 Ma1. & 165,0000 & 167,4093 & 0,9089 & 0,9928 & 166,6681 & $-1,6681$ \\
\hline 30 Jun. & 140,0000 & 168,9030 & 0,9674 & 0,8153 & 136,8301 & 3,1699 \\
\hline $31 \mathrm{Jul}$. & 173,0000 & 173,4525 & 1,3256 & 0,9086 & 151,6765 & 21,3235 \\
\hline 32 Ago. & 183,0000 & 179,0101 & 1,7488 & 0,9196 & 157,5654 & 25,4346 \\
\hline 33 Set. & 146,0000 & 177,9819 & 1,4711 & 0,8879 & 162,6586 & $-16,6586$ \\
\hline 34 Out. & 151,0000 & 176,6915 & 1,1949 & 0,9252 & 168,2621 & $-17,2621$ \\
\hline 35 Nov. & 152,0000 & 174,6754 & 0,8738 & 0,9562 & 172,7936 & $-20,7936$ \\
\hline 36 Dez. & 181,0000 & 173,5992 & 0,6788 & 1,1029 & 195,4753 & $-14,4753$ \\
\hline $37 \mathrm{Jan}$. & 198,0000 & 176,0832 & 0,8593 & 1,0720 & 185,2105 & 12,7895 \\
\hline $38 \mathrm{Fev}$. & 248,0000 & 184,2556 & 1.5906 & 1,1359 & 194,4285 & 53,5715 \\
\hline 39 Mar. & 212,0000 & 185.4659 & 1,5526 & 1,1545 & 214,9322 & $\begin{array}{l}-2,9322 \\
\end{array}$ \\
\hline $40 \mathrm{Abr}$. & 181,0000 & 183,5512 & 1,2059 & 1,0866 & 206,5260 & $-25,2560$ \\
\hline 41 Mal. & 174,0000 & 183,3326 & 1,0634 & 0,9863 & 183,4282 & $\begin{array}{l}-9,4282 \\
\end{array}$ \\
\hline 42 Jun. & 174.0000 & 188,7486 & 1,4987 & 0,8313 & 150,3414 & 23,6586 \\
\hline $43 \mathrm{Jul}$. & 152,0000 & 186.8046 & 1.1544 & 0,8943 & 172,8530 & $-20,8530$ \\
\hline 44 Ago. & 192,0000 & 191,0820 & 1,4667 & 0,9324 & 172,8531 & 19,1469 \\
\hline 45 Set. & 179,0000 & 193.9052 & 1,6024 & 0,8932 & 170,9700 & 8,0300 \\
\hline 46 Out. & 201,0000 & 198,7695 & 1.9286 & 0,9381 & 180,8801 & 20,1199 \\
\hline 47 Nov. & 226,0000 & 206,0464 & 2,4634 & 0,9773 & 191,9061 & 34,0939 \\
\hline 48 Dez. & 279,0000 & 215.1796 & 3.1304 & 1,1319 & 229.9604 & 49.0396 \\
\hline
\end{tabular}

RESLLTADOS DA FASE DE PREVISÃO

PERIODO OBSERVAÇÃO COMPONENTE TENDENCIA FATOR PREVISÃO ERRO ACUMULADO PERMANENTE SAZONAL

\begin{tabular}{lrllllrr}
\hline 49 Jan. & 259,0000 & 221,8044 & 3,4798 & 1,0863 & 234,0261 & 24,9739 & 1,2993 \\
50 Fev. & 274,0000 & 227,6446 & 3,7189 & 1,1460 & 255,8086 & 18,1014 & 2,2540 \\
51 Mar. & 280,0000 & 233,0641 & 3,8859 & 1,1615 & 267,1411 & 12,8589 & 3,0260 \\
52 Abr. & 223,0000 & 232,1923 & 3,4101 & 1,0677 & 257,4644 & $-34,4644$ & 1,0691 \\
53 Mai. & 199,0000 & 230,5282 & 2,9027 & 0,9678 & 232,3630 & $-33,3630$ & $-0,5555$ \\
54 Jun. & 227,0000 & 239,3762 & 3,4972 & 0,8488 & 194,0510 & 32,9490 & 0,9332 \\
55 Jul. & 167,0000 & 234,4520 & 2,6551 & 0,8670 & 217,2107 & $-50,2107$ & $-1,1511$ \\
56 Ago. & 219,0000 & 236,7723 & 2,6216 & 0,9313 & 221,0805 & $-2,0805$ & $-1,3578$ \\
57 Set. & 229,0000 & 241,9416 & 2,8764 & 0,9012 & 213,8294 & 15,1706 & $-0,7230$ \\
58 Out. & 216,0000 & 242,6336 & 2,6579 & 0,9309 & 229,6608 & $-13,6608$ & $-1,3913$ \\
59 Nov. & 290,0000 & 253,0086 & 3,4296 & 1,0026 & 239,7209 & 50,2791 & 0,8474 \\
60 Dez. & 363,0000 & 266,0757 & 4,3934 & 1,1668 & 290,2703 & 72,7279 & 3,2052
\end{tabular}


Verificamos que o fator sazonal $c_{t}$ é maior em março em todos os anos, indicando uma frequêencia maior de homicídios neste mês. Seguem-se os meses de dezembro, janeiro e fevereiro, apresentando estimativas dos parâmetros de sazonalidade sempre maiores que 1,0. Observa-se que os outros meses apresentam $c_{t} \quad 1,0$, sendo que, no mês de junho, eles são pequenos, próximos de 0,80 , indicando que é neste mês que ocorrem menos homicídios.

A previsão do número de homicídios mês a mês, para o ano de 1980, encontra-se na Tabela 12. Para verificar a adequação do modelo, utiliza-se um teste com o erro acumulado padronizado (tracking signal cumulatives error). No nosso caso, o valor do erro acumulado padronizado não deve exceder a $3,65^{23}$ Observando a última coluna da Tabela 12 , verificamos que o modelo proposto é adequado para previsão dos homicídios no ano de 1980.

Distribuição Mensal dos Acidentes de Trânsito de Veículos a motor e das Lesões Ignoradas se Acidental ou Intencionalmente Infligidas.

\section{GRĀFICO 3}

Distrib. Mensal dos Óbitos por Ac.Veic. Motor c Lesões lgnora.Acid.ou Intenc. 1976 a 1980

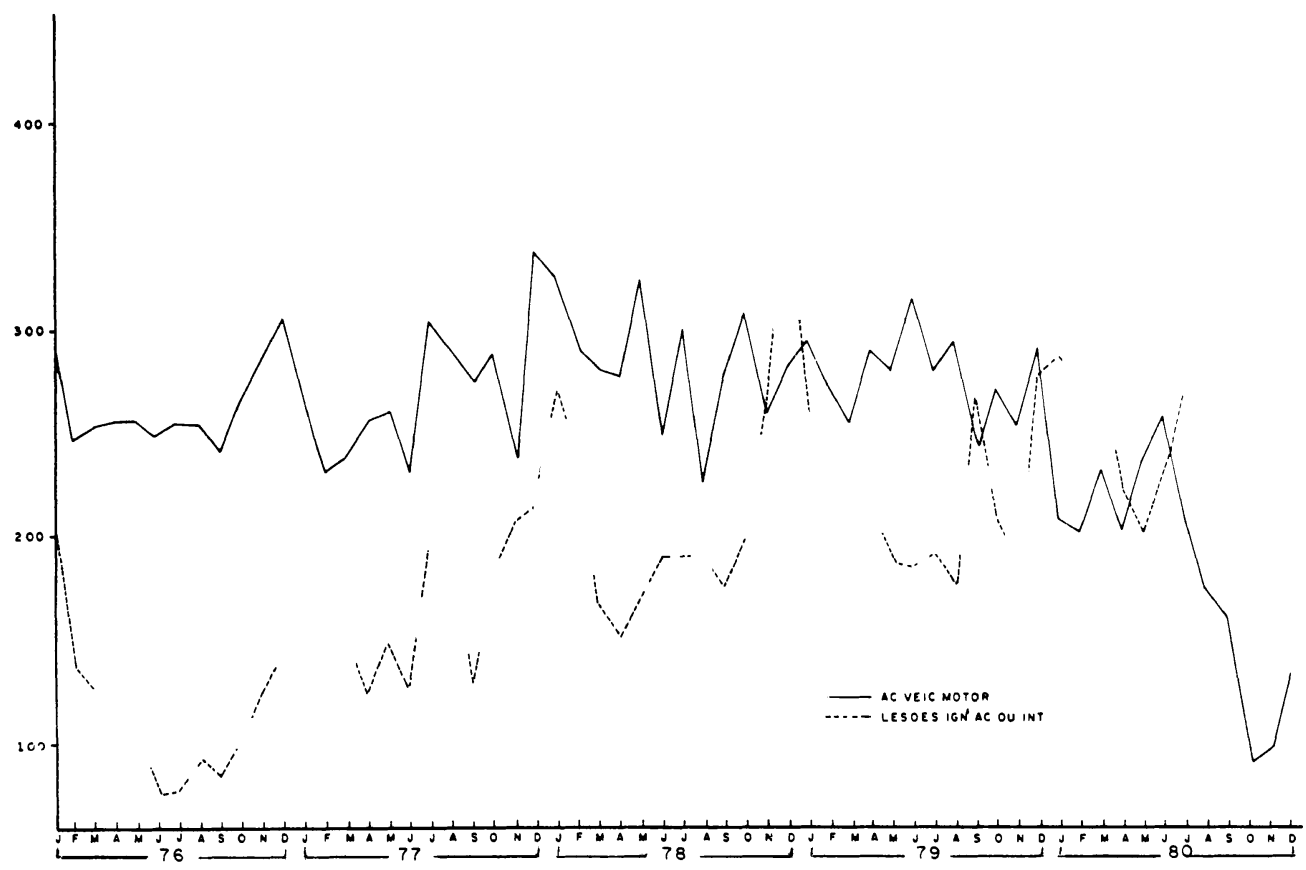

Analisando o Gráfico 3, que apresenta as distribuições mensais dos óbitos por acidentes de trânsito e daqueles classificados como lesôes ignoradas, observamos que os aciden- 
tes de trânsito estão oscilando em torno de um valor médio, de 1976 a 1979, mostrando uma tendência decrescente a partir de 1980, particularmente no 2 ? semestre deste ano. Ressalta-se que os óbitos que se ignora se acidentais ou intencionais mostram aumento repentino, justamente nos meses em que os acidentes de trânsito apresentam grande declínio, de julho a dezembro de 1980 . Tal fato vem a confirmar, mais uma vez, que os óbitos por acidentes de trânsito estão sendo indevidamente classificados.

Pela análise da Tabela 13, comprova-se mais uma vez a mudança repentina de comportamento nos óbitos por acidentes de trânsito, já que todos os resultados preditivos foram rejeitados, com valores absolutos para os testes dos erros acumulados padronizados, ultrapassando em muito o valor crítico de 3,65 .

\section{TABELA 13}

Resultado do Ajuste da Série Temporal dos Obitos por Acidentes de Trânsito, Segundo o Modelo de Winter, Estado do Rio de Janeiro - 1976 a 1980

\begin{tabular}{|c|c|c|c|c|c|c|}
\hline \multirow[b]{2}{*}{ PERIODO } & \multicolumn{5}{|c|}{ RESULTADO DA FASE DE INICIALIZAÇÃO } & \multirow[b]{2}{*}{ RESIDUO } \\
\hline & OBSERVAÇÃO & $\begin{array}{l}\text { COMPONENTE } \\
\text { PERMANENTE }\end{array}$ & TENDENCIA & $\begin{array}{l}\text { FATOR } \\
\text { SAZONAL }\end{array}$ & $\begin{array}{r}\text { MODELO } \\
\text { AJUSTADO }\end{array}$ & \\
\hline $1 \mathrm{Jan}$ & 296,0000 & 263,1482 & 0,5440 & 1,0966 & 0,0 & 0,0 \\
\hline $2 \mathrm{Fev}$ & 246,0000 & 262,3171 & 0,4065 & 0,9622 & 254,8589 & $-8,8589$ \\
\hline $3 \mathrm{Mar}$ & 253,0000 & 263,5454 & 0,4887 & 0,9458 & 247,8293 & 5,1707 \\
\hline $4 \mathrm{Abr}$ & 255,0000 & 263,0828 & 0,3935 & 0,9865 & 261,2732 & $-6,2732$ \\
\hline 5 Mai & 255,0000 & 261,2930 & 0,1752 & 1,0171 & 169,9087 & $-14,9087$ \\
\hline $6 \mathrm{Jun}$ & 249,0000 & 261,3828 & 0,1667 & 0,9541 & 249,5411 & $-0,5411$ \\
\hline $7 \mathrm{Jul}$ & 254,0000 & 258,9050 & $-0,0978$ & 1,0323 & 272,3560 & $-18,3560$ \\
\hline $8 \mathrm{Ago}$ & 253,0000 & 259,1265 & $-0,0659$ & 0,9706 & 250,9353 & 2,0647 \\
\hline 9 Set & 240,0000 & 258,3853 & $-0,1334$ & 0,9407 & 244,2442 & $-4,2442$ \\
\hline 10 Out & 268,0000 & 258,3918 & $-0,1194$ & 1,0345 & 267,0334 & 0,9666 \\
\hline $11 \mathrm{Nov}$ & 288,0000 & 265,4246 & 0,5958 & 0,9629 & 243,1160 & 44,8840 \\
\hline $12 \mathrm{Dez}$ & 308,0000 & 268,0725 & 0,8010 & 1,1083 & 292,9333 & 15,0667 \\
\hline $13 \mathrm{Jan}$ & 266,0000 & 264,9270 & 0,4064 & 1,0827 & 294,8508 & $-28,8508$ \\
\hline $14 \mathrm{Fev}$ & 231,0000 & 261,5444 & 0,0275 & 0,9503 & 255,3026 & $-24,3026$ \\
\hline $15 \mathrm{Mar}$ & 239,0000 & 260,2400 & $-0,1057$ & 0,9417 & 247,3973 & $-8,3973$ \\
\hline $16 \mathrm{Abr}$ & 255,0000 & 259,8872 & $-0,1304$ & 0,9857 & 256,6235 & $-1,6235$ \\
\hline $17 \mathrm{Mai}$ & 260,0000 & 259,1357 & $-0,1925$ & 1,0151 & 264,2085 & 4,2085 \\
\hline 18 Jun & 229,0000 & 256,1033 & $-0,4765$ & 0,9451 & 247,0630 & $-18,0630$ \\
\hline $19 \mathrm{Jul}$ & 304,0000 & 261,4568 & 0,1065 & 1,0518 & 263,8777 & 40,1223 \\
\hline 20 Ago & 288,0000 & 266,8372 & 0,6339 & 0,9869 & 253,8734 & 34,1266 \\
\hline $21 \mathrm{Set}$ & 274,0000 & 271,0405 & 0,9908 & 0,9512 & 251,6134 & 22,3866 \\
\hline 22 Out & 288,0000 & 272,9866 & 1,0863 & 1,0376 & 281,4111 & 6,5889 \\
\hline $23 \mathrm{Nov}$ & 235,0000 & 269,5708 & 0,6361 & 0,9492 & 263,8982 & $-28,8982$ \\
\hline $24 \mathrm{Dez}$ & 339,0000 & 275,5552 & 1,1710 & 1,1266 & 299,4795 & 39,5205 \\
\hline $25 \mathrm{Jan}$ & 325,0000 & 280,2422 & 1,5226 & 1,0943 & 299,6196 & 25,3804 \\
\hline $26 \mathrm{Fev}$ & 291,0000 & 285,4304 & 1,8891 & 0,9607 & 267,7747 & 23,2253 \\
\hline $27 \mathrm{Mar}$ & 281,0000 & 288,9810 & 2,0553 & 0,9463 & 270,5674 & 10,4326 \\
\hline $28 \mathrm{Abr}$ & 278,0000 & 289,6853 & 1,9202 & 0,9818 & 286,8765 & $-8,8765$ \\
\hline $29 \mathrm{Mai}$ & 324,0000 & 295,7432 & 2,3339 & 1,0271 & 295,9993 & 28,0007 \\
\hline $30 \mathrm{Jun}$ & 249,0000 & 292,8835 & 1,8146 & 0,9309 & 281,7207 & $-32,7207$ \\
\hline $31 \mathrm{Jul}$ & 300,0000 & 293,2751 & 1,6723 & 1,0475 & 309,9761 & $-9,9761$ \\
\hline
\end{tabular}


PERIODO OBSERVAÇÃO COMPONENTE TENDENCIA FATOR MODELO RESIDUO PERMANENTE SAZONAL AJUSTADO

\begin{tabular}{lrrrrrr}
\hline $32 \mathrm{Ago}$ & 244,0000 & 284,7507 & 0,6526 & 0,9569 & 291,0852 & $-67,0852$ \\
$33 \mathrm{Set}$ & 280,0000 & 286,7454 & 0,7868 & 0,9550 & 271,4880 & 8,5120 \\
$34 \mathrm{Out}$ & 309,0000 & 289,0742 & 0,9410 & 1,0423 & 298,3308 & 10,6692 \\
$35 \mathrm{Nov}$ & 259,0000 & 287,4417 & 0,6837 & 0,9420 & 275,2847 & $-16,2844$ \\
$36 \mathrm{Dez}$ & 282,0000 & 282,4521 & 0,1163 & 1,1074 & 324,6077 & $-42,6077$ \\
$37 \mathrm{Jan}$ & 297,0000 & 280,8948 & $-0,0510$ & 1,0887 & 309,2078 & $-12,2078$ \\
$38 \mathrm{Fev}$ & 283,0000 & 282,9026 & 0,1549 & 0,9667 & 269,8130 & 13,1870 \\
$39 \mathrm{Mar}$ & 253,0000 & 280,7021 & $-0,0807$ & 0,9396 & 267,8567 & $-14,8567$ \\
$40 \mathrm{Abr}$ & 290,0000 & 282,8342 & 0,1406 & 0,9883 & 275,5142 & 14,4858 \\
$41 \mathrm{Mai}$ & 280,0000 & 281,4185 & 0,0150 & 1,0223 & 290,6541 & $-10,6541$ \\
$42 \mathrm{Jun}$ & 316,0000 & 290,1121 & $-0,8558$ & 0,9546 & 261,9539 & 54,0461 \\
$43 \mathrm{Jul}$ & 281,0000 & 287,5608 & 0,5151 & 1,0370 & 304,7905 & $-23,7905$ \\
$44 \mathrm{Ago}$ & 295,0000 & 291,1089 & 0,8184 & 0,9653 & 275,6504 & 19,3496 \\
$45 \mathrm{Set}$ & 240,0000 & 285,8333 & 0,2090 & 0,9377 & 278,7988 & $-38,7988$ \\
$46 \mathrm{Out}$ & 271,0000 & 282,1375 & $-0,1815$ & 1,0300 & 298,1311 & $-27,1311$ \\
$47 \mathrm{Nov}$ & 252,0000 & 279,7903 & $-0,3980$ & 0,9358 & 265,5981 & -13.5981 \\
$48 \mathrm{Dez}$ & 281,0000 & 275,5457 & $-0,7827$ & 1,0942 & 309,3950 & -28.3950
\end{tabular}

RESULTADOS DA I'ASE DF: PREVISÃO

PERIODO OBSERVAÇÃO COMPONENTE TENDENCIA FATOR PREVISÃO ERRO ACUMULADO PERMANENTE SAZONAL PADRONIZADO

\begin{tabular}{lrlllllr}
\hline $49 \mathrm{Jan}$ & 218,0000 & 263,5833 & $-1,9007$ & 0,0495 & 299,1438 & $-81,1438$ & $-3,1694$ \\
$50 \mathrm{Fev}$ & 202,0000 & 253,7749 & $-2,6914$ & 0,9411 & 252,9595 & $-50,9595$ & $-4,6948$ \\
$51 \mathrm{Mar}$ & 231,0000 & 250,3002 & $-2,7698$ & 0,9371 & 235,9056 & $-4,9056$ & $-5,3074$ \\
$52 \mathrm{Abr}$ & 203,0000 & 241,2104 & $-3,4018$ & 0,9663 & 244,6420 & $-41,6420$ & $-6,5207$ \\
$53 \mathrm{Ma}$ & 236,0000 & 236,7647 & $-3,5062$ & 1,0185 & 243,1144 & $-7,1144$ & $-7,3225$ \\
$54 \mathrm{Jun}$ & 257,0000 & 238,6516 & $-2,9669$ & 0,9730 & 222,6771 & $-34,3229$ & $-5,7660$ \\
$55 \mathrm{Jul}$ & 209,0000 & 230,5647 & $-3,4789$ & 1,0174 & 244,3951 & $-35,3951$ & $-6,8747$ \\
$56 \mathrm{Ago}$ & 184,0000 & 221,6138 & $-4,0261$ & 0,9451 & 219,2157 & $-35,2157$ & $-7,9358$ \\
$57 \mathrm{Set}$ & 159,0000 & 210,3835 & $-4,7465$ & 0,9104 & 204,0368 & $-45,0368$ & $-8,9969$ \\
$58 \mathrm{Out}$ & 89,0000 & 187,7549 & $-6,5349$ & 0,9466 & 211,8065 & $-122,8065$ & $-9,9976$ \\
$59 \mathrm{Nov}$ & 96,0000 & 169,4231 & $-7,7144$ & 0,8804 & 169,5814 & $-73,5814$ & $-10,9164$ \\
$60 \mathrm{Dez}$ & 131,0000 & 155,4100 & $-8,3443$ & 1,0565 & 176,9493 & $-45,9493$ & $-11,9008$
\end{tabular}

Observa-se que de 1976 a 1979, os fatores de sazonalidade $c_{t}$ mostram-se maiores sempre no mês de dezembro, seguido de janeiro (Tabela 13). Estes são os meses que apresentam maior número de acidentes fatais.

Taxas de Mortalidade Segundo as Principais

Causas Externas nos Municípios do Estado do

Rio de Janeiro e suas Correlações com

Indicadores Sócio-Econômicos - 1980

$\mathrm{Na}$ Tabela 14, apresentamos as taxas de mortalidade padronizadas por idade, segundo as principais causas externas e região de residência. Verificamos que o Interior do estado é a região que apresenta maior taxa de mortalidade por to. das as outras causas, mas é na região metropolitana que predominam as causas externas. A taxa de homicídios é maior na capital, enquanto que as taxas por acidentes de trânsito se igualam no Interior e no Município do Rio, sendo bem menor na região do Grande Rio. No entanto, é esta região que apresenta maior coeficiente na categoria das lesões ig-

Cadernos de Saúde Pública, R.J., 2 (1): 19-41, jan/mar,1986. 
PESQUISA

noradas no que tange à intenção.

TABELA 14

Taxas de Mortalidade (por 100.000 Habitantes. Padronizadas por Idade. Segundo as Principais Causas Externas e Todas as Outras Causas e Região de Residência - Estado do Rio de Janeiro, 1980

Causas

Região

Residência Ot. Causas C. E.st. Ac. Trans. Homıcidıo Suicídio Ac.ou Int.

\begin{tabular}{lrrrrrr}
\hline Rio & 680.37 & 101.85 & 22,63 & 33,58 & 2,46 & 27,95 \\
Grande Rio & 748.17 & 107.60 & 13,02 & 25,22 & 1,97 & 46.54 \\
Interior & 808.67 & 88.60 & 22,34 & 13.52 & 3,30 & 23,13 \\
Estado & 724.34 & 99.11 & 19,42 & 26,08 & 2.47 & 32,05
\end{tabular}

Ccm o objetivo de pesquisar associações entre a situação sócio-econômica de cada município e a mortalidade por causas externas, foram calculadas as taxas de mortalidade por acidentes de trânsito, suicídios, homicidios e lesões ig-noradas se acidentais ou intencionais, em todos os municipios do Estado do Rio de Janeiro, para o ano de 1980. Para o Município do Rio de Janeiro, os coeficientes foram calculados por região administrativa.

Essas taxas foram estimadas utilizando-se como denominador o número de residentes em cada município, referido no censo de 1980 , e como numerador o número de óbitos segundo cada causa externa, em cada município. Estas taxas foram posteriormente corrigidas, multiplicando-se por um fator resultante da divisão do número total de óbitos no Estado pelo número total de óbitos, excluindo-se aqueles cujo município de residência era ignorado.

Como indicadores sócio-econômicos, foram escolhidos:

a) o percentual de indivíduos que vivem em área urbana (URB).

b) percentual de indivíduos com mais de 5 anos, analfabetos ou com menos de um ano de instrução (ANALF).

c) percentual de famílias com rendimento médio mensal menor que um salário mínimo (excluem-se as famílias de declaração de renda no denominador) (RISM).

Esses indicadores foram obtidos através do censo do Estado do Rio de Janeiro de $1980^{8}$.

Calcularam-se, então, as correlaçōes entre estas variáveis, sendo consideradas 87 observações, 63 nos municípios do Estado e 24 nas regiões administrativas da capital.

A matriz de correlaçöes entre os indicadores sócio-econômicos e as taxas de mortalidade por causas externas estão na Tabela 15. Verifica-se que a taxa de homicídios é a mais explicativa da taxa de todas as causas externas, apresentando uma correlação de 0,80 com esta última. Fica evidente, também, a alta correlação das mortes violentas com o nível 


\section{PESQUISA}

ACTRANS. - Taxa de mortalidade por acidentes de trânsito

LESIGN. - Taxa de mortalidade por lesōes ignoradas se acidental ou intencionalmente infligidas

HOMIC. - Taxa de mortalidade por homicídios

SUIC. - Taxa de mortalidade por suicídios

ANALF. - Percentual de indivíduos com mais de 5 anos, analfabetos ou com menos de um ano de instrução

R1SM - Percentual de famílias com rendimento médio mensal menor que um salário mínimo

E interessante observar que foi nas regiões com melhor nível sócio-econòmico, Copacabana e Botafogo, que se encontrou taxa de homicídios quase igual a taxa de suicídios. Por outro lado, na região portuária, por exemplo, a taxa de homicídios é 20 vezes maior que a de suicídios.

\section{COMENTÁRIOS FINAIS}

Pela análise dos resultados apresentados, verificamos que, na década de 70, no Estado do Rio de Janeiro, os óbitos devidos às causas externas cresceram acentuadamente.

A taxa de mortalidade por homicídios é uma das mais altas do mundo, e vem crescendo cada vez mais, a uma taxa de $14 \%$ ao ano.

A importância da violência como fator de mortalidade já foi anteriormente descrita em trabalhos realizados na década de $1970^{4,28,29}$. Neste período, as mortes violentas em adultos jovens americanos tiveram aumento de elevada proporção, enquanto que a mortalidade por outras causas mostrou declínio. Esse aumento da mortalidade foi atribuído em grande parte, ao rápido crescimento da taxa de homicídios, que, no grupo etário de 25-34 anos, chegou a ultrapassar a taxa por acidentes de trânsito. No México, no perí. odo de $70-74$, as mortes violentas também tiveram comportamento semelhante ${ }^{13}$.

Diversos pesquisadores têm investigado os fatores possivelmente envolvidos nas tendências da mortalidade por homicídios $23,4,12,21,22,27,28,29$. Estudos revelam que um dos fatores fortemente associado é a proliferação do uso de armas de fogo na população $2,28,29$. Aqui no Estado, em 1980 , cerca de $90 \%$ dos homicídios por meios conhecidos foram cometidos com armas de fogo.

Outros autores, como, por exemplo, Rodriguez ${ }^{2}{ }^{7}$, consideram ainda que o número de homicídios em uma população mantém relação inversa ao seu grau de desenvolvimento sócio-econômico e cultural. E, de fato, nos países desenvolvidos como Japão, Hungria e Inglaterra, a taxa de suicídios é bem maior do que a de homicídios, contrariamente ao que ocorre no Estado do Rio.

No entanto, analisando a mortalidade por causas externas segundo os municípios do estado, a violência mostrouse altamente associada à urbanização.

Fazendo uma análise específica só para as regiões administrativas da capital, áreas consideradas 100\% urbanas pela 
FIBGE $^{8}$, a hipótese levantada por Rodriguez ${ }^{26}$ foi mais uma vez observada, já que a taxa de homicídios mostrou uma correlação positiva com os indicadores de educação e renda, a saber: quanto maior o analfabetismo e maior a proporção de famílias de baixa renda, maior a taxa de homicídios e menor a taxa de suicídios. Mostrou-se, também, que é em Copacabana a região administrativa de melhor nível sócioeconômico, que se encontra a menor razão entre a taxa de homicídios e a de suicídios, igualando-se nesta área.

Neste levantamento de mortalidade por causas externas, revelaram-se também de alta importância os acidentes de trânsito. Os atropelamentos em escolares mostram-se de real gravidade, constituindo-se na primeira causa de morte para crianças de 5-14 anos.

Esforços vêm sendo desenvolvidos no sentido de estabelecer as diversas causas que intervêm nos acidentes de trânsito ${ }^{11}, 13,15,16,20$. Um fator descrito como altamente relacionado é o uso do álcool pelo condutor do ve ículo, antes da ocorrência do acidente ${ }^{10,13}$ Nada podemos afirmar, em virtude da falta de informações sobre o percentual de fatalidades em que houve perda de controle do veículo. Sabemos, no entanto, que mortes por acidentes de trânsito são mais freqüentes nos fins-de-semana e no mês de dezembro.

Vários outros componentes podem ainda ser considerados, como as condições mecânicas dos veículos, o estado das vias de trânsito, falhas de sinalização, falta de passarelas, as condições meteorológicas e até mesmo o fator humano, do condutor ou pedestre ${ }_{2}$ que é muitas vezes decisivo na ocorrência de fatalidade $\mathrm{i}^{13,25}$.

Esses fatores devem ser investigados na busca de soluções para a prevenção dos acidentes de trânsito. Poucas informações, no entanto, nos são fornecidas sobre a forma de ocorrência dos acidentes nas estatísticas de mortalidade do Estado do Rio nos últimos anos. Em 1980, entre os acidentes fatais que não foram atropelamentos, $98 \%$ foram codificados como de natureza não especificada. A condição de condutor, passageiro, motociclista, ciclista ou pedestre dada pelo 4 ? dígito da rubrica é também ignorada na grande maioria dos registros.

A falta de informações adequadas nas declarações de óbito constituem grave problema para uma efetiṿa análise de mortalidade. No ano de $1980,32 \%$ dos óbitos por causas externas foram rubricadas como lesões que se ignora se foram acidental ou intencionalmente infligidas. Esse percentual, de 1976 para 1980, dobrou de tamanho. Se supusermos que esta taxa de crescimento permanece constante, podemos esperar que, em 1984, 64\% dos óbitos por causas externas serão classificados nesta categoria. 


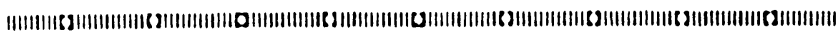

Deaths due to accident and violent causes were studied in Rio de Janeiro, Brasil, from 1976 to 1980. Spatial and time distributions of the main causes of death were analysed. Motor vehicle traffic accidents had shown to be the first cause of death, mainly among school age children (5.14 years old). An increase of $70 \%$ in homicide rates was observed and homicides are actually the first cause of death among young adults (20-29 years old). A substantial proportion of misclassifications was found, as indicated by the great number of deaths classified as "other violences".

\section{REFERÊNCIAS BIBLIOGRÄFICAS}

1. BARROS, M. B. de A. Mortalidade por violências e acidentes no Brasil. Campinas, Dept? de Medicina Preventiva e Social, FCM/UNICAMP, 1984. (Trabalho apresentado no 3 ? Seminário Latino Americano de Medicina Social, Ouro Preto).

2. BROWNING, C. Handguns and homicide. J. Amer. Med. Assoc., $236: 2198.200,1976$.

3. CABILDO H. Panorama epidemiológico de los decórdenes psiquiátricos en la República Mexicana. Salud Publ. Mex., 13 : 53-63, 1971

4. CONSTANTINO, J. et alii. An epidemiologic study of homicides in Allengheny County, Pennsylvania. Amer. J. Epidemiol. $106: 314-24,1977$.

5. DIVISÃO NACIONAL DE EPIDEMIOLOGIA. Estatistica de mortalidade, Brasil, 1980. Brasília, 1983.

6. DIXON, W. J. \& BROWN, M. B. Biomedical computer programs P-series. Bekerley, Univ. California Press, 1977.

7. FUNDAÇÃO INSTITUTO BRASILEIRO DE GEOGRAFIA E ESTATIISTICA. Censo demográfico; Rio de Janeiro. $8^{\circ}$. re. cenceamento geral do Brasil - 1970. Rio de Janeiro, 1973. v. $1, t .1$ (Série Regional).

8. FUNDAÇÃO INSTITUTO BRASILEIRO DE GEOGRAFIA E ESTATISTICA, Censo demográfico; Rio de Janeiro. 9. recenceamento geral do Brasil. - 1980. Rio de Janeiro, 1983. v. 1, t. $4, n^{\circ} \cdot 18$.

9. FUNDAÇÃO INSTITUTO DE DESENVOLVIMENTO ECONO. MICO E SOCIAL. Estado do Rio de Janeiro: estatísticas do sistema de saúde. Rio de Janeiro, FIDERJ/DIGES/SIPE, 1977.

10. HAVARD. J.D.J. Alcohol and the driver. Br. Med. J., I 1595-7, 1978.

11. HAVARD, J. D. J. Mortality from motor vehicle accidents in the 15-24 year age groups. World Health Stat., 32 (3) 225-34, 1979.

12. HEALTH and medical conditions of drivers: effects on road safety. WHO Chron: $35,(6): 237,1981$.

13. HUELKE. D. F. \& GIKAS, P. W. Causes of deaths in automo- 
bile accidents. J. Amer. Med. Assoc., 203 :1100-7, 1968.

14. JIMENEZ-NAVARRO, R. El fenómeno de las muertes violentas en México. Salud Publ. Méx., 20 : 755-73, 1978.

15. LAURENTI, R. et alii. Alguns aspectos epidemiológicos da mortalidade por acidentes de trânsito de veículo a motor na cidade de São Paulo, Brasil. R. Saúde públ., 6 : 329-41, 1972.

16. MAC CARROL, J. R. \& HADDOW W. J. A controled study of fatal automobile accidents in New York city. J. Chron. Dis., $15: 811-26,1962$.

17. MANUAL da classificação estatística internacional de doenças lesões e causas de óbito: 8 a rev., 1965. São Paulo, Centro Brasileiro de Classificação de Doenças, 1969.

18. MANUAL da classificação estatística internacional de doenças, lesões e causas de óbitos. 9? rev., 1975. São Paulo, Centro Brasileiro de Classificação de Doenças, 1978.

19. MELLO JORGE, M. H. P. Mortalidade por causas violentas no município de São Paulo, Brasil, I. Mortes violentas no tempo. R. Saúde públ., $14: 343-57,1980$.

20. MELLO JORGE, M. H. P. Mortalidade por causas violentas no município de São Paulo, Brasil. II Mortes acidentais. $R$. Saúde públ., $14: 475-508,1980$.

21. MELLO JORGE, M. H. P. Mortalidade por causas violentas no município de São Paulo, Brasil. III. Mortes intencionais. $R$. Saúde públ., 15 :165-93, 1981.

22. MELLO JORGE, M. H. P. Mortalidade por causas violentas no Município de São Paulo, Brasil. IV. A Situação em 1980. $R$. Saúde públ., $16: 19-41,1982$.

23. MONTGOMERY, D. C. \& JOHNSON, L. A. Forecasting and time series analysis. New York, Mc-Graw-Hill, 1976.

24. MORTALIDADE por causas externas no Brasil. Dados/RADIS, $3(8): 1,1985$.

25. NUNES, E.D. Violência e morte. Revisando o tema. Campinas. Dept ${ }^{\circ}$ de Medicina Preventiva e Social FCM/UNICAMP, 1984. (Trabalho apresentado no 3 \% Seminário Latino Americano de Medicina Social, Ouro Preto).

26. OLIVARES URBINA, C. Mortalidade por acidentes de trânsito - Distrito Federal, México. Salud Publ. Méx., 25 : 307-20, 1983.

27. RODRIGUEZ, L. El crimen como máxima expressión de patologia social. Salud Publ. Méx., 15 : 59-66, 1973.

28. RUSHFORTH, Norman et alii. Violent death in a metropolitan county; changing patterns in homicide (1958-1974). N. Engl. J. Med. $297: 531-8$.

29. WEISS, N. S. Recent trends in violent deaths among young adults in the United States. Amer. J. Epidemiol., 103 . 416-22, 1976.

30. WORLD HEALTH STATISTICS ANNUAL. Geneve, WHO, 1981.

31. WORLD HEALTH STATISTICS ANNUAL. Geneve, WHO, 1982.

Cadernos de Saúde Pública, R.J., 2 (1):19-41,jan/mar,1986. 